University of Rhode Island

DigitalCommons@URI

Open Access Master's Theses

1978

\title{
THE EFFECT OF VEHICLE ON ANTIPERSPIRANT EFFICACY
}

Melanie H. Smith

University of Rhode Island

Follow this and additional works at: https://digitalcommons.uri.edu/theses

Recommended Citation

Smith, Melanie H., "THE EFFECT OF VEHICLE ON ANTIPERSPIRANT EFFICACY" (1978). Open Access

Master's Theses. Paper 227.

https://digitalcommons.uri.edu/theses/227

This Thesis is brought to you for free and open access by DigitalCommons@URI. It has been accepted for inclusion in Open Access Master's Theses by an authorized administrator of DigitalCommons@URI. For more information, please contact digitalcommons-group@uri.edu. 
TEE EPFECT OP VEHICLE ON ANTIPERSPIRANT EPFICACY

BY

. MELANIE H. SMITH
A THESIS SUBMITTED IN PARTIAL PULFIITMENT OF THE REQUIREMENTS FOR THE DEGREE OF MASTER OF SCIENCE
IN

PBARMACY

UNIVERSITY OF RHODE ISIAND

1978 
MASTER OF SCIENCE THESIS

OF

METANIE H. SMITH

Approved:

Thesis Committee

Major Professor



UNIVERSITY OF RHODE ISLAAND

1978 


\section{ABSTRACT}

The effect of formulation factors on the efficacy of the antiperspirant agent, aluminum chlorhjdrate, was studied. The formulation variables include the various carrier vehicles for the topically applied active ingredient. Qunatification of antiperspirant efficiency was evaluated by a generally accepted gravimetric technique by application of a known amount of active ingredient to the axillae of human volunteers.

Aluminum chlorhydrate was solubilized in a cream base, an aqueous lotion, and a hydroalcholic base, and was suspended in a solid stick. Aluminum chlorhydroxy allantoinate was incorporated into all vehicles for its therapeutic and cosmetic properties. All test antiperspirant products were selected on the basis of cosmetic elegance and acceptability.

The four vehicles containing aluminum chlorhydrate were compared for efficacy by a well-recognized gravimetric procedure during a normal work day in each subject's normal work environment. A pretest sweat collection was used as a blocking factor in designing the 4 by 4 , split plot, Latin Square. Post-test sweat collection data were evaluated 
statistically using the geometric mean of treatment results. All ratio treatment means were converted to percent sweat reduction to determine antiperspirant efficiency.

The carrier vehicle does not affect antiperspirant efficacy. However, efficacy differences were observed as a function of solution versus suspension. Treatment response in terms of percent sweat reduction was: aqueous lotion, 38.0\%; hydroalcoholic solution, $32.4 \%$; cream base, $31.8 \%$, and solid stick, -6.2\%. Statistical analysis indicated that the side treated may be selected randomly without compromising the results. Sweat weights may be affected by temperature, muscular exercise, or emotional stress without affecting antiperspirant effectiveness. 


\section{ACKNOWLEDGEMENTS}

Sincere thanks are extended to Drs. George E. Osborne and Joan M. Lausier, whose teaching and courses provided the researcher with an excellent background in cosmetic technology. Their advice during experimental work, suggestions during the writing of the thesis, and constructive criticism throughout the conduct of the project were then, and are now, greatly appreciated. The author also is grateful to Drs. C. T. Rhodes, C. I. Smith, and Anthony N. Paruta for their criticiam, cooperation, and suggestions. The assistance of the other faculty members of the College of Pharmacy of the University of Rhode Island also is acknowledged.

Special thanks are offered to Dr. William D. Lawing, Jr., Department of Computer Science and Experimental Statistics of the University of Rhode Island, for his generous assistance in statistical design and analysis; Dr. R. N. Chadha, Chairman of the Board, Carroll Products, Inc., Wood River Junction, Rhode Island, and S. B. Mecca, Chemical Director, Schuylkill Chemical Company, Philadelphia, for guidance, samples, and continuing interest in this project; Mr. Greg Adams and Mr. Andrew M. Rubino of Reheis Chemical Company, Berkeley Heightz, New Jersey, for antiperspirant agents and formulation advice; $\mathrm{Mr}$. 
Robert C. Vonachen of the Kendall Company, Boston, for Webril pad samples; Cooper Scientific Corporation, Watertown, Massachusetts, for Surgex samples; and ICI Americas Incorporated, Wilmington, Delaware, Croda, Incorporated, New York, and Amerchol, Edison, New Jersey, for chemical supplies and formularies.

The researcher is extremely grateful to the volunteers who devoted their time, ideas, and axillae to complete this study.

The researcher is indebted to her husband, Bruce, for providing moral support and exceptional editorial and typing skills. 
TABIE OF CONTENTS

PAGE

ABSTRACT....................................ii ACKNOWLEDGEMENTS............................ IV TABLE OF CONTENTS..............................vi IIST OF TABLES...............................vii FIGURES.....................................vilit

I. OBJECTIVES..............................1

II. INTRODUCTION..............................

III. METHODOLOGY $\ldots \ldots \ldots \ldots \ldots \ldots \ldots \ldots \ldots \ldots \ldots \ldots \ldots \ldots \ldots \ldots \ldots$

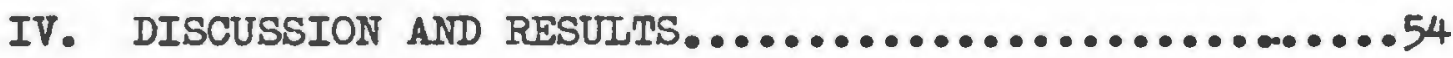

v. CONCLUSIONS................................66

VI. APPEIDICES..............................67

VII. REFERENCES...............................98 


\section{IIST OF TABLES}

TABLE

PAGE

1. Comparison of the Chemical Properties of Aluminum Chloride and Aluminum

Chlorhydrate............................17

2. Pretest Sweat Collection Data Used for Blocking 4 by 4, Split Plot, Latin Square.......46

3. 4 by 4 , Split Plot, Latin Square Design.........48

4. Analysis of Variance for 4 by 4, Split Plot, Latin Square........................51

5. ANOVA of Post-Test Data.....................55

6. Antiperspirant Treatment Efficacy and Dosage. 


\section{FIGURES}

PIGURE

PAGE

1. A Diagram of Eccrine and Apocrine Glands in Relationship to Other Cutaneous Apperidages.......5

2. A Comparison of $\mathrm{pH}$ Values of Aluminum Chlorhydrate, Aluminum Sulphate, and Aluminum Chloride Solutions..................18

3. The Pretest Sweat Ratios of Light-Sweating Side to Heavy-Sweating Side (L/H) of Subject Pairs (B) versus Subjects by Sides ( $\angle\left\{\left(B D_{k p}\right)\right)$ Illustrating the Subjects by Sides Interaction Occurs in Subject Pair 3.................57

4. The Effects of Weeks (C) versus Weeks by Sides ( $\leqslant\left(C D_{m p}\right)$ ) Indicating an Interaction During Week 3, a Possible Result of Emotional Stress on Sweating. .59 


\section{OBJECTIVES}

Many drugs and cosmetics are applied topically, resulting in various kinds of dermal activity. These items include various types and classes of emollients, antiinfectives, sunscreens, keratoljtics, antibacterials, and antiperspirants. The activity of topically applied drugs depends on such factors as solubility, particle size, acid-base function, percutaneous absorption, and stability. In some instances, drug efficiency has been shown to be dependent on the carrier vehicle in which the drug is placed (1-10).

The literature is replete with reports of the efficacy of dermally applied antiperspirant agents (10-20); however, there is a paucity of published information on the effect of vehicle on antiperspirant efficacy. This gap in such data became pronounced very recently for two reasons: the Food and Drug Administration's Over-The-Counter Drug Review Panel's review of antiperspirants for ". . safety, toxicity, and efficacy of the product and its component ingredients" (21); and the Federal Register May 1977 decision to phase out fluorocarbon-propelled aerosols (22).

The present study is concerned with:

1. The effect of vehicle on antiperspirant efficacy.

2. The influence of the active ingredient's state, 
2

(e.g., suspension versus solution) on antiperspirant efficacy.

3. Quantification of antiperspirant efficiency using a gravimetric technique (23-27) under normal conditions of use.

4. Developing a statistically sound experimental design, which eliminates side treated differences, to evaluate antiperspirant efficacy data. 


\section{INTRODUCTION}

A. Anatomy and Physiology of the Sweat Glands

The axilla is the cavity beneath the shoulder joint, commonly referred to as the armpit. It is a unique skin site in that it is a moist, intertriginous area containing both sebaceous glands and sudoriferous or sweat glands. The latter are present in the stratum corneum or surface horny lajer, a keratinous lajer of flat, denucleated, dead cells, approximately 600 um thick in the horng pads of the palms and soles and 15 um thick in the membranous horny layers such as the axillae (28).

Perspiration has a physiologically important role. Insensible perspiration is the loss of water in the form of vapor from the body into the air through the skin and respiratory passages. Sensible perspiration, known as sweat, is the visible delivery of sweat droplets from the sweat glands to the skin surface. The principal functions of perspiration are the maintenance and control of body temperature and waste excretion, but it also contributes to the hydration and plasticization of the stratum corneum $(29,30)$.

There are two distinct functional and anatomical structures responsible for the production of sensible perspiration: the apocrine and eccrine sweat glands. 
4

The eccrine sweat glands are distributed throughout the skin surface, with the exception of the lips and genital organs. Most are in the palms and soles. Thej are tubular structures consisting of a secretory coil in the lower dermis with a duct leading directly to the skin surface (Figure 1). The eccrine sweat glands are well-developed and functional from birth throughout an individual's life span (32). They aid in the regulation of body temperature and maintenance of skin elasticity (33).

The apocrine glands are distributed anong the axillae, breasts, and urogenital areas. They are structurally similar, to the eccrine glands, but they are larger in size and fewer in number. The apocrine glands consist of a coiled secretory tubule in the dermis, leading upward to the duct attached to a hair follicle. At least one apocrine gland is attached to each hair follicle in the axillae (34). In children, small, undifferentiated apocrine glands lie deep in the dermis. From the seventh year to adolescence the glands become progressively larger and well-differentiated, but not functional. Hhey develop at puberty and remain functional for life, although they decrease in size and activity after menopause (35). Extensive studies of apocrine gland activity have attempted to correlate structural and functional variations of the apocrine gland with hormonal changes without success $(36,37)$. Researchers regard apocrine sweating as a secondary sexual characteristic, associated with sexual attraction among peoples 


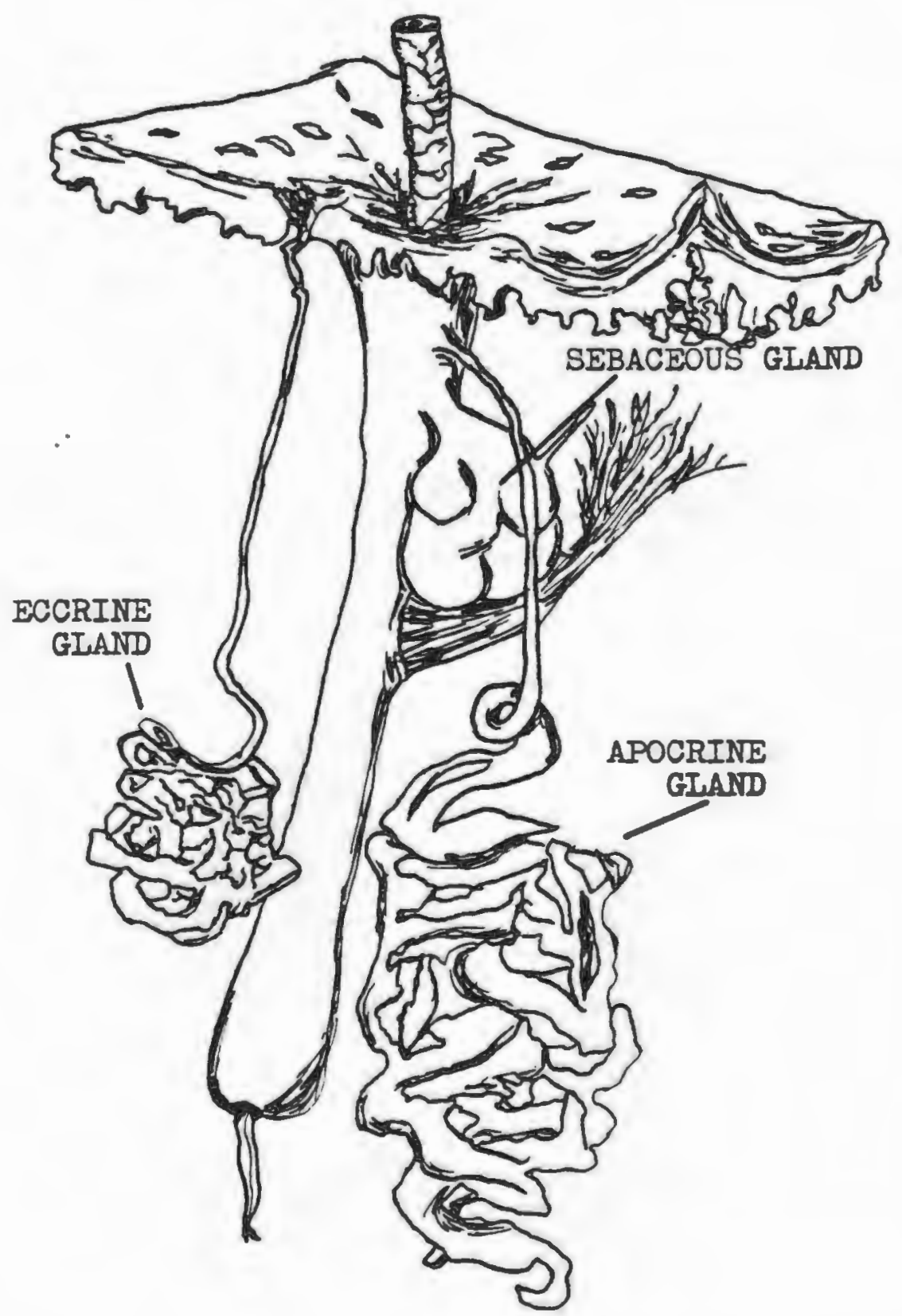

Figure 1. Diagram of eccrine and apocrine glands in relationship to other cutaneous appendages (31). 
throughout the evolution of the human species $(29,38,40)$.

B. The Physiology of Sweat Secretion

Sweat secretion is controlled by the sympathetic nervous system. The temperature-regulating center in the hypothalamus controls thermal sweating, while emotional sweating, most likely to occur in the palms, soles, and axillae, is controlled by a cortical center.

Eccrine sweating is a continuous process that is innervated cholinergically by acetylcholine and adrenergically by epinephrine. The nerve fibers surrounding the eccrine sweat glands respond to emotional as well as thermal stimuli.

The actions of acetylcholine are either muscarinic or nicotinic. Pilocarpine and adrenalin produce a direct muscarinic response of local eccrine sweating; while indirect, widespread, nicotinic response will follow intradermal injections of acetylcholine, metacholine, and carbachol (41).

Anticholinergics (e.g., atropine) and ganglionic blockers (e.g., hexamethonium) inhibit eccrine sweating. Atropine has been used clinically to treat hyperhidrosis. However, the severe parasympathetic side effects and toxicity associated with atropine's frequent use and its tendency to hydrolyse rapidly has limited its usefulness to experimentation only $(42-44)$. Various anticholinergic salts and esters have exhibited greater stability. In one study 
topical application of $1 \%$ scopolamine hydrobromide for five consecutive days effectively inhibited sweat for one month (45). Recent studies showed glycopyrrolates produced topical suppression of eccrine sweat. Their use was accompanied by a marked decrease in local or systemic adverse effects (46).

Apocrine sweating, adrenergically innervated by epinephrine and emotional stimuli, is an intermittent process with a refractory period Irom 24 to 48 hours $(33,47)$. The physical stimulus of compressing the axillary skin in a gentle, sliding motion, as in the case of the axilla being rubbed by a swinging arm during walking, causes the appearance of apocrine sweat (37).

Direct pharmacological stimulation of the apocrine glands results from intradermal injections of epinephrine, norepinephrine, and neosynephrine. Pilocarpine increases the metabolic rate of apocrine glands. New evidence suggests that apocrine sweating may be induced by the contractions of the muscles surrounding the apocrine sweat tubules and not solely by adrenergic stimulation $(37,44)$.

Dibenamine selectively inhibits apocrine sweating, but it is too toxic for clinical use. The imidazolines, Regitine and Priscoline, are safe and effective in reducing apocrine sweating (44). 
C. Perspiration Composition

Perspiration, a mixture of organic and inorganic matter in a ratio of approximately $1: 3$, is sterile and odorless. Eccrine glands secrete a clear, colorless, watery lluid that is $99 \%$ water. The remainder is a mixture of inorganic ions such as sodium, chloride, potassium, calcium, iron, manganese, magnesium, and copper together with certain.organic compounds such as lactic, citric, and ascorbic acids, urea, and nitrogenous compounds $(38,48,49)$. Eccrine sweat has a $\mathrm{pH}$ of 4.0-7.0, the higher $\mathrm{pH}$ range usually from axillary perspiration. Intertriginous surfaces, such as the axillae, inhibit sweat evaporation causing a neutralization and dilution of free acids which promote hydrolysis of nitrogenous material and result in a

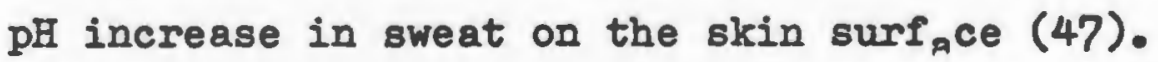

The apocrine slands secrete on opalescent, turbid-white fluid that emerges from the hair follicles and spreads over the skin surface, which, if not diluted by eccrine sweat, dries rapidly to form a glistening film. $(47,50)$. This fluid contains water, sodium chloride, proteins, lipids, and a high ammonia content which results in a pH of 6.0-7.5 $(49,51)$. Generally, the $\mathrm{pH}$ of apocrine sweat is $0.5 \mathrm{pH}$ units higher than eccrine sweat in a given individual. 'his is attributed to the high ammonia concentration in apocrine sweat (52). 
D. Disorders of the Sweat Glands

There are cases of functional disorders of the sweat glands. Hyperhidrosis or excessive perspiration is one of the major disorders. General hyperhidrosis is usually a result of excessive heat, exertion, or certain drugs as acetylcholine, or adrenalin. Iocal hyperhidrosis usually affects the axillae or palms or soles. It originates in the apocrine glands as a result of staphjlocci infections or from an initial dermatitis from deodorant/antiperspirant products (53). Anhidrosis, a rarely occuring disorder, is the diminution or even cessation of sweat. Bromidrosis, perspiration with an offensive smell, is usually associated with the apocrine glands and is a direct result of bacterial decomposition. Chromidrosis, abnomally colored perspiration, also is attributed to bacterial activity. Certain toxic and disease states produce hemahidrosis, which is bloody perspiration, or urehidrosis, which is perspiration containing urine substances (54).

E. Perspiration Malodor

Although perspiration secreted by the sweat glands is sterile and free of odor, the axillae provide an excellent odor-producing surface. There are sufficient nutrients from apocrine secretions plus a warm, moist, neutral pH medium in which skin bacteria seem to thrive. Apocrine secretions that reach the skin surface are subject to attack by microorganisms, especially gram-positive staphylocci and diphtheroids, resulting in bacterial 
decomposition and the characteristic body odor referred to as caprylic. Axillary hair and heary clothing, ideal collection sites for bacteria, increase perspiration malodor. Contaminated eccrine secretions, which produce a vague, indistinct odor unlike apocrine-generated odor, are not considered the main cause of offensive body odor $(36,38,54$, 55).

P. Factors Influencing Perspiration Output

1. Racial differences. Perspiration is characteristic of race, family, and individual. No significant differences in sweat volume or sweat distribution have been found in the eccrine sweating patterns in Negro and Caucausian subjects, however, apocrine glands of Hegroes are larger, more numerous, and have shorter refractory periods than Caucausians. Moreover, chromidrosis occurs more frequently in Negroes. Mongolian races have relatively inactive apocrine glands. In any event, females have more, but smaller apocrine glands than males regardless of race. Humans produce an average of one to three pints of eccrine sweat in 24 hours, regardless of race, sex, or individual. Eccrine sweat accounts for the major portion of total volume of axillary perspiration with only small volumes of apocrine and sebaceous secretions (50). 2. Thermal and emotional stimuli. Quantitative studies of varying thermal and emotional stimuli have noted differences in perspiration volume $(11,24,56-58)$. High 
temperatures of $80-100^{\circ} \mathrm{F}$ and high humidities with little air movement cause an overproduction of axillary sweat because cooling is impaired.

Mental stimuli ranging from mental arithmetic to apprehension to arguments continue to elicit increased sweating over a long time period of 1-1\% hours $(57,58)$.

Simultaneous emotional and thermal stimuli produce an additive effect on sweat output. Minor emotional stimuli are greatly magnified at higher temperatures, resulting in an increased axillary sweating rate (58).

3. Diet and health. Higher metabolic rates, whether caused by fever, thyroid function, or rich, spicy foods, cause greater heat production and, in turn, increased sweating $(58,59)$. A low salt diet of 100 $\mathrm{mg} /$ day shows a 20-25\% decrease in sweat output compared to a $40 \mathrm{~g} /$ day salt intake diet (58). Water intake has little effect on sweat rate, but a substantial loss of water causes a substantial loss of sodium chloride $(29,60)$. The response of the sweat glands to a given stimulus, whether it be thermal, emotional or gustatory, is a function of the three factors, mainly because it is related to the acetylcholine produced (61).

4. Other factors. Body posture affects the sweat rate. If a subject is in a sitting or reclining position for an extended time period, the body adjusts and the sweat rate decreases. If there is a sudden change in trunk 
position, there is a substantial increase in sweat rate $(11,58)$. A dramatic increase in sweat rate and volume occurs with muscular exercise; this increase is dependent upon the preexercise sweating rate (62). There are conflicting reports about the effect of dominant-handedness on sweating. In one study, $78 \%$ of the left-handed subjects and $60 \%$ of the right-handed subjects had a greater sweating rate on the side opposite the dominant hand (63). Other studies indicate that the dominant-handed side sweats more (24). there is a significant variation in right to left axillae sweat ratios from day to day in the same individual $(9,11)$. Generally, the side with greater sweat volume remains the same. Axillary sweat collection devices can greatly alter the sweating rate. 'the force of a vial pressed against a flat collection pad reduced sweating rate (58). A comfortable, jet snugly fitting collection device is necessary to insure proper sweat collection with no chance of sweat evaporation.

G. Control of Perspiration

1. History. Throughout history man has searched for ways to inhibit body odor and perspiration with perfumes and cosmetics. "From ancient Egyptian times to the 1800 s bath oils and perfumes were used to scent the body. In 1888, the first trademarked deodorant, Mum, a perfumed wax base to plug pores, was marketed. In 1914, the first commercial 
aluminum chloride-based deodorant, Odo-Ro-No, was produced. In addition to its deodorant properties, it was later discovered to have excellent antiperspirant activity. Since then, researchers have tested various chemicals to help stop odor and wetness. The introduction of aluminum chlorhydrate in 1947, an antiperspirant agent that was non-irritating and minimized fabric damage, accelerated consumer use of antiperspirant/deodorant products. In 1950, hexachlorophene was added to antiperspirant formulations to enhance their antibacterial properties, but extensive research on the brain damaging effects of hexachlorophene resulted in termination of its use a decade later. The introduction of roll-on lotions in 1950 and aerosol antiperspirants in 1968 caused the rapid expansion of the antiperspirant market. A decade later the controversy over the damage to the ozone layer caused by fluorocarbons in aerosols prompted their phase out. 'Ihis action, reported in the May 1977 Federal Register, redirected antiperspirant manufacturers' attention to the familiar roll-on and stick vehicles. In 1975, manufacturers began the shift from aerosols to manual pump sprays. Today, antiperspirant manufacturers are evaluating the safety, toxicity, and efficacy of both their well-established and experimental products as directed by the 1972 Food and Drug Administration's Over-The-Counter Drugs Antiperspirant Panel. This panel 
will have a major impact on future trends in the antiperspirant market $(21,22,64-70)$.

2. Mechanism of action of antiperspirants. Personal hrgiene, deodorants, and antiperspirants are the main methods of controlling the objectionable aspects of perspiration--offensive odor and excessive sweat gland secretions.

Deodorants help control body odor by masking it and/or reducing its intensity. Hey conform to the Pood, Drug, and Cosmetic Act's definition of a cosmetic as "... an article intended to be rubbed, poured, sprinkled, or sprayed on ... the human body .. Por cleansing ... (or) .. promoting attractiveness .." (71).

Deodorizing agents for the human body include antibacterials such as neomycin, neutralizing agents such as sodium bicarbonate, and astringents such as aluminum chloride $(55,72-74)$.

Antiperspirants control and reduce the flow of perspiration. Plechner and deNavarre $(75,76)$, classify antiperspirants as drugs because of their anhidrotic action. Antiperspirants also conform to the Food, Drug, and Cosmetic Act's definition of a drug, ". . articles intended to affect the structure or any function of the body of man . . " (71).

The astringent aluminum salts contained in the majority of commercial antiperspirants possess both 
deodorant and antiperspirant actions. Their deodorant action involves their antibacterial and chemical properties. The acid pH of aluminum compounds, which inhibits bacterial decomposition of sweat secretions, prevents odor development; and the chemical combination of the aluminum salts and the odoriferous substance neutralizes the odor $(36,77,78)$. The antiperspirant action of aluminum salts is still disputed. They may act.directly on the sweat gland, or form a plug or block in the sweat duct, or involve the electro-physiological potential along the sweat duct $(79,80)$. Papa (81) studied the alteration of permeability of eccrine sweat ducts treated with aluminum chloride. He concluded that the aluminum salt increases the transductal absorption of sweat. Hermann's and Sulzberger's theory (82) is the one that is recognized most widely. They observed that antiperspirents produce an inflammatory reaction accompanied by swelling and an expansion of the horny layer around the sweat duct causing its constriction and reducing sweat delivery to the skin surface (79).

3. Antiperspirant agents. A variety of effective topical antiperspirant agents have been tested. Anticholinergics such as scopalamine esters are very effective anhidrotics, but have toxic effects when used on a long-term basis (41-46). Formaldehyde and aluminum salts irritate the skin and damage clothing $(14,83)$. Zirconium was very popular in the 1950s, but frequent incidences of 
granulomas were reported (83-85).

Aluminum chlorhydrate is the major antiperspirant agent used in todey's commercial products. It is a basic aluminum chlorhydroxide complex with an atomic ratio of aluminum to chloride of $2: 1$ as compared to $1: 3$ in the aluminum chloride. A $20 \% \mathrm{w} / \mathrm{w}$ solution has a $\mathrm{pH}$ of 4.2 compared to aluminum chloride's pH of 2.0-2.5 (Table 1). This higher $\mathrm{pH}$, a result of the large proportion of hydroxyl groups, reduces skin irritation, minimizes clothing destruction, is consistent with the skin's acid mantle, and prevents rapid hydrolysis of the antiperspirant agent. This provides pH stability over a wide range of concentrations as illustrated in Figure 2 (86).

Aluminum chlorhydrate is very water soluble. A $50 \% \mathrm{w} / \mathrm{w}$ solution in water is clear, colorless, slightly viscous; it is soluble with othyl alcohol, making it ideal for use in the manual pump sprajs.

Aluminum chlorhydrate is available in a variety of particle sizes making it adaptable for varying uses and vehicles. The impalpable grade of solid aluminum chlorhydrate is designed for aerosol and suspensoid stick application (87). Sodium aluminum chlorhydroxy lactate, pH 8.5, was developed for use in sodium stearate based sticks and systems requiring buffering (88). Aluminum chlorhydroxide-proplyene glycol complex is being used more in aerosols, pump sprays, and stick antiperspirants. It 
TABLE 1

COMPARISON OP THE CHEMICAI PROPERTIES

OF

ALUMINUM CHLORIDE AND ALUMINUM CHLORHYDRATE

\begin{tabular}{lcc}
\hline & ALUMINUM CHIORIDE & ALUMINUM CHLORHYDRATE \\
\hline Formula & $A 1 \mathrm{Cl}_{3}$ & $\mathrm{Al}_{2}(\mathrm{OE})_{5} \mathrm{Cl}$ \\
$\mathrm{pH}$ & $2.00-2.50$ & $4.00-4.25$ \\
$\mathrm{Al:CI}$ & $1: 3$ & $2: 1$ \\
\hline
\end{tabular}




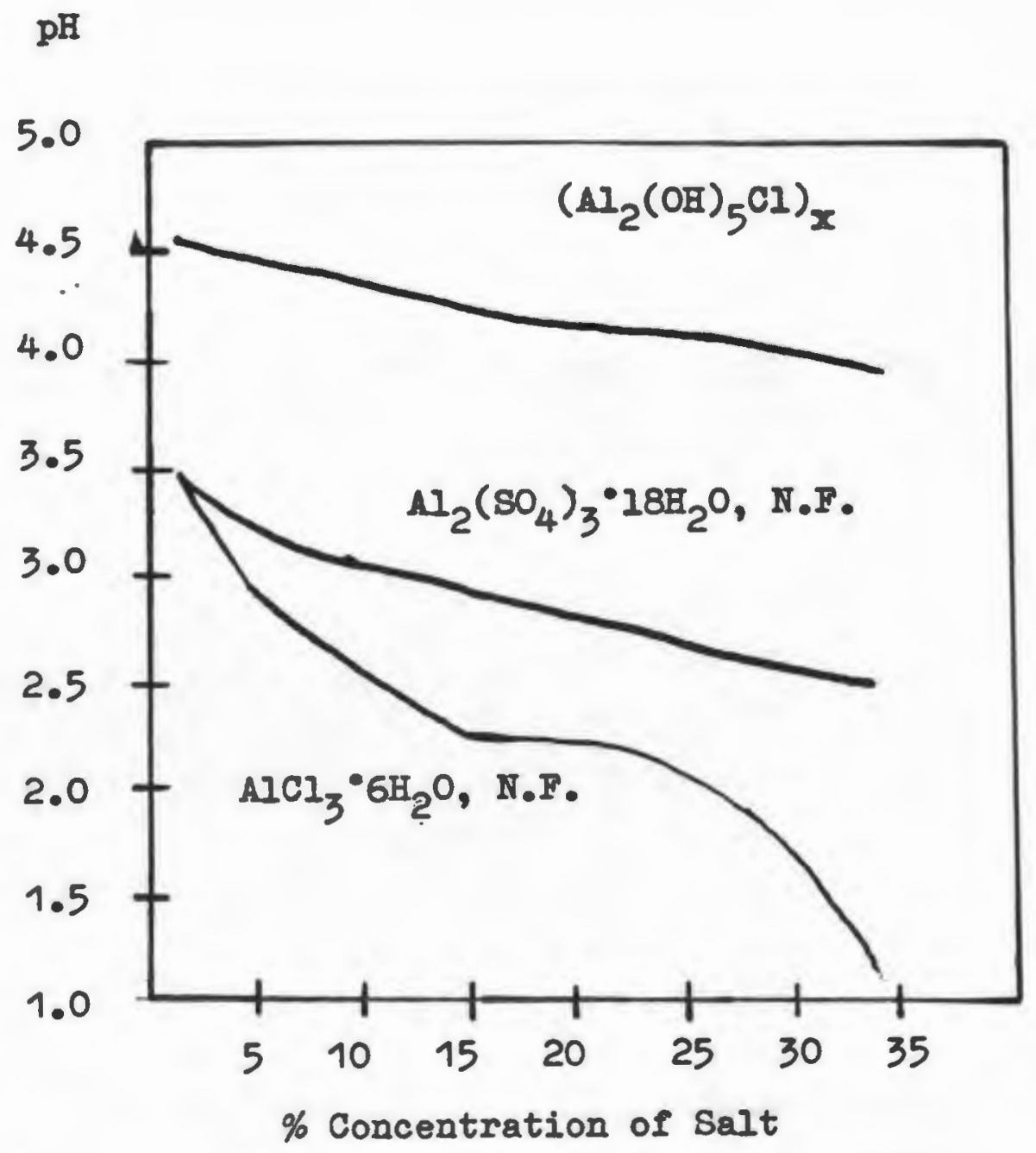

Figure 2. Comparison of $\mathrm{pH}$ values of aluminum chlorhydrate, aluminum sulphate, and aluminum chloride solutions (86). 
is soluble in both water and anhydrous alcohol up to concentrations of at least $50 \%(69,89)$.

Aluminum chlorhydrosg allantoinate, "a stable, white, odorless powder which combines the antiperspirent and astringent bacteriostatic properties of aluminum chlorhydrate with the therapeutic and cosmetic properties of allantoin," (90), is used in conjunction with aluminum compound antiperspirants. It is compatible in a $\mathrm{pH}$ range of 1-6.1. It is emplojed in concentrations from 0.2-0.3\% for its anti-irritant, keratoljtic, bacteriostatic, astringent, moisturizing, anti-pruritic, and healing actions. It has been proven beneficial in preventing or alleviating dermatitis associated with antiperspirant products (20). Alcohol-soluble aluminum chlorhydroxg allantoinate is a molecular form of the allantoin complex used in concentrations from $0.2-0.5 \%$ in hydroalcoholic and aerosol formulations ( 90$)$.

A modified form of aluminum chlorhydroxy allantoinate is available for use as the single active ingredient in concentrations from 6-20\% in antiperspirant lotions and creams. A $20 \%$ solution of modified aluminum chlorhydroxy allantoinate has a pH of 3-5 and contains $19.8 \%$ aluminum chlorhydroxide as an active antiperspirant ingredient and $0.2 \%$ allantoin complex for its therapeutic and cosmetic effects. Alcohol-soluble, modified aluminum chlorhydroxy allantoinate is employed in concentrations from $6-10 \%$ in 
aerosol antiperspirants (20).

B. Antiperspirant Formulation and Vehicular Considerations

It is generally recognized that aluminum chlorhydrate effectively inhibits perspiration, but its activity is influenced by formulation excipients (e.g., vehicle), mode of application, concentration of agent, and the amount of antiperspirapt applied $(4,6,9,91)$. In addition, vehicle plays an important role in consumer accoptability. A vehicle that is physically and chemically compatible with the antiperspirant agent, is dermatologically safe, and results in a cosmetically acceptable and elegant product, is necessary.

A number of factors must be considered when formulating antiperspirants. Aluminum salts other than the aluminum chlorhydroxide complexes are sufficiently acidic to cause a salting out effect of the metal ions; they are rapidly hydrolyzed, and will react readily with soap bases such as free stearic acid to form an undesirable product. To maintain their antiperspirant efficacy and minimize skin irritation, a pH consistent with the acid mantle of the skin is sought, and the addition of buffers such as urea are necessary. The use of aluminum chlorhydroxide complexes have solved many of these problems. Marketed antiperspirant vehicles include creams, roll-ons, sticks, aerosols, and pump sprays. نureams and 
roll-ons are oil-in-water or water-in-oil emulsions with the active ingredient dissolved in the aqueous phase. The addition of nonionic surfactants such as Tween 60 and Arlacel 60 or Arlacel 165 emulsify and thicken the product. These surfactants are nonirritating to the skin and are compatible with aluminum salts. By varying the concentrations of additive ingredients such as Veegum, cetyl alcohol, or spermaceti, the viscosity and consistency of the product can be altered. Glycerin may be added for emolliency and to prevent the formation of aluminum crystals (92-94). To maintain antiperspirant efficacy in a cosmetically suitable stick, the impalpable grade of aluminum chlorhydrate is suspended in a wax base, or the aluminum chlorbydroxide-proplyene gljcol complex is dissolved in a stearamide-based stick $(95,96)$. An alcoholic diluent and neutral, acidic-aluminum-compatible gelling agents, such as stearamide and sucrose distearate, are the building blocks of the stick. Isopropyl myristate is added for emolliency. Volatile silicones are added to reduce tackiness, drag and drying time $(96,97)$.

Alcohol-soluble forms of aluminum chlorhydroxide such as aluminum chlorhydrate, $50 \% \mathrm{w} / \mathrm{w}$ solution, or aluminum chlorhydroxide-propylene glycol are used in the commercial manual pump spray antiperspirants. The alcohol-based manual pump sprays require the addition of 
valve lubricants, such as stearic acid or Arlamol $\mathrm{E}$, to prevent aluminum salt crystallization which causes valve clogging and spray sputtering. Arlamol $\mathbf{E}$ and volatile silicones are also added for emollience and reduction of tackiness and drying time. Powder-in-oil suspensions for use in pump sprays are being tested $(96,98,99)$.

Perfumes, emollients, thickeners, coloring agents, and other component ingredients are Irequently added to enhance product appearance and application. Aerosols require different formulation considerations. Thej are powder-in-oil suspension concentrates pressurized with a propellant. The active ingredient is suspended in the powder phase, while the oil phase is composed of high molecular weight carboxplic acid esters and perfume oils. Epoxy linings prevent the aluminum salt from corroding the metal containers. Aluminum chlorhydroxide-propylene glycol complex has proven advantageous for use in aerosols because it is effective, safe, and may be packaged in low-cost metal containers with Iluorocarbon propellants $(70,89,100,101)$.

I. Assessing Antiperspirant Efficacy

1. In vitro. In vitro methods are used for preliminary study of a potential antiperspirant's activity. Govett and deNavarre (14) developed the protein precipitation test, a qualitative or 
semi-quantitative test for astringency. One cc of astringent salt solution is added to a $1: 1$ mixture of egs albumin and distilled water. The rate of protein precipitation, the nature of the precipitate, and solubility characteristics over a 12-hour period of various astringents are then evaluated subjectively. Protein precipitation testing confirms the superiority of aluminum chlorhydrate over other aluminum salts as a protein precipitant, despite its higher $\mathrm{pH}$.

A standardized, reproducible frog skin test was developed by Govett and deNavarre (14) to measure antiperspirant activity. Frog skin is treated with varying concentrations of astringent salt solutions. The area of skin shrinkage and decrease in water permeability of the frog's skin is used to measure the astringent action of the solutions. Christian et al. $(16,18)$ expanded this test by evaluating the effect of antiperspirant preparations on the permeability of sodium and iodide ions on frog membranes. The extent of iodide penetration was measured by radioactive tracer technique.

2. In vivo. Pilocarpine-induced sweating in mouse and rat foot pads has been used for testing antiperspirant activity (15). However, animal eccrine sweat glands differ histologically from man's $(11,102)$, limiting animal testing of antiperspirants to measuring irritant potential of the agent. 
Human testing is necessary for assessing efficacy and consumer acceptance of a finished antiperspirant product. The quest for knowledge of sweat gland function and antiperspirant efficacy has resulted in a variety of techniques for visualizing, assessing, and collecting sweat (103).

Wada and Takagaki (104) developed a colorimetric technique thät permits visualization of sweat patterns on the skin. Skin surfaces painted with a starch-alcohollc iodine mixture produce a characteristic blue-black color in distinct patterns corresponding to the presence of active sweat pores as moisture reaches the skin surface. Papa $(105,106)$ modified their mixture with a castor oil suspension. This prevented environmental moisture from interfering with the results while permitting the presence of sweat droplets to be visualized.

Visual techniques are used mainly in studying sweat gland activity $(59,107)$. To measure antiperspirant activity a reduction in magnitude of color relative to an untreated area is evaluated visually. Sweat patterns and numerical dot counts taken by blotting paper towels or pressing ping-pong balls against the tested area have been adapted to semi-quantify this method $(106,108)$. However, this method does not take into account the size of the sweat droplets or the sweat intensity (9). 
Continuous recording techniques have been used to quantify sweat production; electronic hygrometers sense and record perspiration electronically. While axillary moisture is continuously removed by a constant flow of gas, an electronic recording device automatically records and plots the sweat ratios or perspiration rates. This procedure eliminates variables involved in sweat collection, such as excessive subject movement (the subject is wired and strapped with electronic devices in a thermal chamber). Positioning of the moisture sensing element over the small test area is critical in obtaining reproducible results. This method is not favored for testing in an area of uneven distribution of sweat glands such as the axilla. It has proven useful in testing on the forearm, an area with an even sweat gland distribution unaffected by reflexes $(11,17,109,110)$.

In spite of the possible errors inherent in the gravimetric technique, such as evaporative loss from pads, lack of distinction between sweat and sebum, positional variation of pad in the axillary vault, and environmental and emotional factors affecting human sweating, it is the most widely used method for testing antiperspirants $(4,5$, $9,11,12,23-27,38,103)$. Since the aim of an antiperspirant is to control perspiration in humans for everday use in all types of environments and situations, the gravimetric technique's antiperspirant efficacy results most closely resemble consumer use of an antiperspirant product. 


\section{6}

This method is simple, inexpensive, and may be used to test a large number of subjects simultaneously, whether in bumidity controlled rooms or at ambient temperatures. It is best adapted for axillary sweat collections $(6,24)$.

Sweat is collected on tared absorbent pads or silica gel tins fitted snugly to the axillae. After a given period of time the pads or tins are remored and weighed for perspiration. Hach subject acts as his own control: one axilla is treated with antiperspirant and the other axilla, the control, is not treated.

Sweat collections carried out in controlled temperature rooms of $100 \% \mathrm{~F}$ and $35 \%$ relative humidity are preceded by a 40-minute conditioning period in the hot room during which the panelists hold pads to their axillae. Hese pads are discarded, since extremely erratic results in sweat weight are obtained during this time. This is followed by two or three 20-minute collection periods using tared pads. This process may be repeated for 2 to 5 days; ratios are then calculated and averaged $(6,11,23-27)$. Under ambient conditions, panelists tape or hamess tared pads for a minimum of three hours during a regular work dey $(6,9,23-25)$. This process is repeated for 2 to 5 days. In both cases, panelists are requested to remove axillary hair and to abstain from personal antiperspirant products for a minimum of one week prior to testing and for the duration of the test. Some investigators have allowed 
the use of deodorant products for personal comfort (9). Sweat collection results are ovaluated statistically by the ratio method or by using a geometric mean. In the ratio method, both axillae serve as controls for a pretest sweat collection period. A pretest perspiration ratio (PR) is calculated as

$$
\text { Weight (mg) perspiration from right axilla }=\text { PR (23). }
$$

A treatment period is then conducted to obtain a sweat ratio of treated axilla to control axilla. Using an arithmetic mean, the pretest and posttest ratios are averaged and antiperspirant efficacy is calculated as

$$
\left(1-\frac{\text { treatment week ratio }}{\text { ratio prior to treatment }}\right) \times 100=\underset{\text { percent }}{\text { sweat }} \text { reduction }(103) .
$$

In 1974, Wooding (26) used the geometric mean in a Sides Subjects Effects Model and produced comparable antiperspirant efficacy results with the ratio method. His model eliminated the need for pretest collection periods, making it a simple, inexpensive, and convenient method for obtaining antiperspirant efficacy data. Other researchers $(4,9,57)$ have adopted this method to determine antiperspirant efficacy. Perspiration weights in milligrams are transformed to natural logarithms before statistical analysis. The treatment mean ( $\left.T^{\prime}\right)$ and control mean ( $C^{\prime}$ ) are then backtransformed to milligrams to calculate the percent 
sweat reduction.

Percent Sweat Reduction $=\left(1-\operatorname{antilog}\left(T^{\prime}-C^{\prime}\right)\right) \times 100$ (4)

J. Previous Studies

The FDA OTC panel directive to review topical drugs as antiperspirants and their component ingredients for their safety, toxicity, and efficacy $(4,21)$ has illuminated the paucity of information regarding vehicular effects on antiperspirant efficacj. Review articles by Uttleg (103), Bakiewicz (11), and Jungermann (6) provide an excellent source of early antiperspirant efficacy studies. However, these studies have been mainly concerned with the efficacy of the antiperspirant agent itself (10-19). The majority of efficacy studies use modifications of Fredell and Read's (23) gravimetric technique introduced in 1951. Recent tests use the same sweat collection procedure, but efficacy calculations are shifting from their aritbmetic mean and adapting Wooding's (26) geometric mean of calculating percent sweat reduction.

Majors and Wild (24) observed the influence of sweating rate, sweat collection conditions, and methods of data analysis on antiperspirant effectiveness. Using a gravimetric technique procedure and a ratio method of calculation; they concluded that: sweat from the dominant 
hand axilla is greater; efficacy results are similar whether taken in a humidity controlled room or during ambient conditions; acillary sweating ratios are more uniform than sweating rates from the same panelist (marked variation of response to antiperspirant application existed among panelists), and formula additives possibly acting as irritants to the axilla affect perspiration output and antiperspirant effectiveness.

Steed (9) collected sweat in silica gel moisture absorbing tins strapped to the body side of the axilla under normal conditions of use. He evaluated three formulations, one comprised of $25 \%$ aluminum chlorhydrate in an aqueous solution thickened with hydroxpethyl cellulose, the second an $11 \%$ aluminum chlorhydrate water-1n-oil emulsion aerosol, and the third, $3.5 \%$ aluminum chlorhydrate suspended in a commercial aerosol. Each participant was arbitrarily designated a treatment axilla to which he applied an unknown amount of test antiperspirant. Test data were calculated using a geometric mean. Percent sweat reduction results exhibited the superiority of the water-in-oil emulsion aerosol. He also observed considerable variation in response among individuals.

Jungermann (6) compared results of antiperspirant efficacy under normal activity and controlled thermal environment. He evaluated a variety of antiperspirant agents in various vehicles for antiperspirant and deodorant efficacy, safety, staining potential, and 
cosmetic acceptability. Using the ratio method and Student t-test he found no significant difference among the active ingredients' effectiveness in the same formulation, but did notice a difference in activity among vehicles and concentrations. He concluded that a controlled thermal environment places stress on the panelist resulting in poor experiment reproducibility, while normal conditions provide reproducible.results and more closely approximate consumer use and opinions of an antiperspirant.

Wooding et al. $(19,26)$ are innovators of experimental design and data analysis procedures associated with gravimetric antiperspirant tests. Using a Latin Square design, Wooding et al. (19) applied similar concentrations of four different antiperspirant agents in aqueous solutions to the backs of panelists and collected sweat under normal temperatures in silica gel tins. The results indicated that the balanced design and analysis was satisfactory, statistically sound, and useful in interpreting antiperspirant efficacy data. A decade later Wooding and Finklestein (26) developed a Sides Subjects Effects Model (SSEM) using a cross-over design. They compared efficacy results under thermal and ambient temperatures using the arithmetic mean of the ratio method and the geometric mean of their method. The SSEM not only gave comparable results to the well-established ratio method, but also eliminated the need for pretest ratios. 
O'Malley and Christian (17) used a continuous recording method to evaluate perspiration properties of six commercial antiperspirant agents and three commercial bases in the forms of a stick, a cream, and a lotion in comparison with a $24 \% \mathrm{w} / \mathrm{w}$ aluminum sulfate solution. All preparations were applied to the subjects' forearms, and the subjects were exposed to varying thermal conditions. A ratio method of calculation indicated that aluminum methionate was the most effective agent and that vehicle did not affect antiperspirant efficacy.

Bretschneider et al. (4) used a gravimetric axillary procedure in a humidity-controlled room to evaluate efficacy of aluminum chlorhydrate type ingredients. Antiperspirant efficacy was calculated using the geometric mean. They tested varying aluminum to halide ratios, multi-ingredient formulations, varying concentrations of single-ingredient formulations, and aqueous versus hydroalcoholic dose forms for efficacy. Definitive results were obtained that showed an increased effectiveness of aqueous vehicles and that optimum concentration efficacy reached a maximum of $15 \%$ aluminum chlorhydrate rather than a plateau. 
III. METHODOLOGI

A. Materials

The following chemicals were used in this study and have been classified by lot number and manufacturer. Glycine, (lot\# G620-1) 1

Arlacel 60, sorbitan monostearate, (lot\# 0602067) ${ }^{2}$ Cetyl Alcohol, N. F., (lot\# 750390007) ${ }^{2}$

Spermaceti, U. S. P., granular, (lot\# 0608196) ${ }^{2}$ Titanium Dioxide, U. S. P., powder, (10t C612248) ${ }^{2}$ Amerchol CAB, (lot\# 153) ${ }^{3}$

Amerchol I-101, multisterol extract, (lot\# 932) 3

Modulan, acetylated lanolin, (lot 351) 3

Solulan 16, ethoxylated (16) lanolin alcohol, (lot\# 1278) 3

Solulan 98, acetyl p. o. e. (10) lanolin alcohol complex, $(\text { lot\# 363) })^{3}$

Glycerine, 96\%, Crystal white, (lot78-206) ${ }^{4}$

1. Aldrich Chemical Co., Inc., Milwaukee, Wisconsin.

2. Amend Drug and Chemical Co., Irvington, New Jersej.

3. Amerchol, Edison, New Jersey.

4. Colgate-Palmolive Co., New York, New York. 
Crodamol IPM, isopropyl myristate, $($ lot\# 331)

Crodesta A 10, acetylated sucrose distearate, (lot\# 3600403-2)5

Procetyl AWS, alcohol and water soluble cetyl alcohol, $(10 \text { \#66) })^{5}$

Super Hartolan, lanolin alcohol, (lot\# 42870) 5

Gulfax, paraffin, (lot\# C211K-I-IP) ${ }^{6}$

Arlacel 165, glycerol monostearate and polyoxyethylene stearate, : $($ lot\# 1855) 7

Arlacel 186, Glycerol fatty acid ester, (lot\# 391) 7

Arlamol E, polyoxppropylene 15 steargl ether, (lot\# 4453B)?

Myrj 52, polyoxyl 40 stearate, U. S. P., $\left(\right.$ lot\# 280) ${ }^{7}$

Tween $60 \mathrm{SD}$, sorbitan monostearate, (lot \# 1153) 7

G-2162, polyoxyethylene (25) propylene glycol stearate, $(10$ \# 119) 7

p-Dioxane, $(\text { lot\#64) })^{8}$

Veegum, colloidal magnesium aluminum silicate, (lot\# c612248) ${ }^{9}$

Chlorbydrol, 50\% w/w Solution, aluminum chlorbydroxide complex, $\left(\right.$ lot\# 6115) ${ }^{10}$

5. Croda, Inc., New York, New York.

6. Gulf Oil Corp., Houston, Texas.

7. ICI Americas Inc., Wilmington, Delaware.

8. Matheson, Coleman, and Bell, E. Rutherford, New Jersey.

9. R. T. Vanderbilt Co., Inc., New York, New York.

10. Reheis Chemical Co., Berkeley Heights, New Jersey. 


\section{4}

MicroDry, Ultrafine, impalpable grade of solid aluminum chlorhydroxide complex, (lot\#5783) 10

Rehydrol, aluminum chlorhydroxide-propylene glycol complex, $($ lot \# 822) 10

Candelilla Wax, (lot\# Tr83074) 11

Carnauba Wax Yellow \#1, "(lot\# 65204) 11

Fluid Silicones 200, 1000. cps, (lot 1A6045) 11

Propylene GlJcol, U. S. P., (lot\# S-353998) 11

Ozokerite Wax, white, (lot\# N70970) 11

Sodium Lauryl Sulfate, dental grade, (lot\# C713284)11

Tenox BHT, (lot\# 101267) 11

Stearic Acid, U. S. P., (lot\# F-1-0562) 11

Alcohol soluble aluminum chlorhydroxy allantoinate modified $^{12}$

Alcohol soluble aluminum chlorhydroxg allantoinate molecular ${ }^{12}$

Aluminum chlorhydroxy allantoinate ${ }^{12}$

Aluminum chlorhydroxy allantoinate modified 12

10. Reheis Chemical Co., Berkeley Heights, New Jersey. 11. Ruger Chemical Co., Irvington, New Jersey. 12. Schuglkill Chemical Co., Philadelphia, Pennsylvania. 
Glassware and common laboratory equipment were supplied by the College of Pharmacy of the University of Rhode Island. Additional supplies and their manufacturers are:

Cotton tipped applicators, 6", (lot\# 22-9186),

ABCO Distributors Inc., Milwaukee, Wisconsin.

Dermicel Hypoallergenic Cloth Tape, $2^{n}$ by 10 gds., Johnson and Johnson, New Brunswick, Hew Jersey.

Irory Soap, Proctor and Gamble, Cincinnati, Ohio.

Surgex Hair Remover Cream, Cooper Scientific Corporation, Watertown, Massachusetts.

Webril Handi Pads, Kendall Fiber Products Division, Walpole, Massachusetts.

Ziploc Storage Bags, $17.8 \mathrm{~cm}$ by $20.3 \mathrm{~cm}$ by $1.75 \mathrm{mil}$, The Dow Chemical Company, Indianapolis, Indiana.

B. Methodology

1. Antiperspirant formulations, To limit the variables in this study, an effective active ingredient was selected to be incorporated in four different vehicles after two antiperspirant agents were tested for solubility and physical and chemical compatibility.

The active agents, modified aluminum chlorhydroxy allantoinate and aluminum chlorhydrate, were tested for solubility and compatibility in four widely used vehicular forms, a cream base, an aqueous roll-on lotion, a solid stick, and an alcohol base such as one used in the manual pump sprays (Appendix A). All products 
were formulated by the researcher to ensure experimental control over concentrations of active ingredients and materials used for component ingredients.

Preliminary dose form and solubility studies were performed with these agents in varying concentrations of hydroalcoholic, propylene glycol/water, propylene glycol/alcohol, and dioxane/water solutions. Noting the concentrations of agent necessary for antiperspirant activity in compatible dose forms led to the selection of $20 \%$ aluminum chlorhydrate as the antiperspirant agent and $0.25 \%$ aluminum chlorhydrox allantoinate for its therapeutic and cosmetic properties.

Three different grades of aluminum chlorhydroxide complex-Chlorhydrol, 50\% w/w solution, MicroDry, Ultrafine, and Rehydrol-were tested in suitable dose forms. Chlorhydrol, $50 \% \mathrm{w} / \mathrm{w}$ solution was employed in concentrations of $40 \%(92-94)$ in preliminary formulations of creams, lotions, and alcohol based solutions (Appendix A). Twenty percent MicroDry, Ultrafine was incorporated directly into a variety of solid sticks. Since Rehydrol $(89,111)$ is equivalent to $75 \%$ by weight of the aluminum chlorhydroxide complex, 26.7\% Rehydrol was used in formulating sticks and alcohol-based solutions to maintain an equivalent amount of active ingredient with the preparations containing Chlorhydrol, $50 \% \mathrm{w} / \mathrm{w}$ solution. For its beneficial therapeutic and cosmetic properties, $0.25 \%$ aluminum 
chlorhydroxy allantoinate $(20,90)$ was incorporated into preliminary formulations of creams and lotions, and the alcohol-soluble form was used in the stick and alcohol solutions.

Modification of established formulations (92-98) was necessary to prepare a simple, jet cosmetically acceptable vehicle. All preliminary formulations were tested and compared for physical and chemical compatibility, stability, and consumer acceptability. One product from each vehicular form was selected for use as the test antiperspirant. Several cream antiperspirants were formulated. Most were similar in composition to the test cream antiperspirant. Forty percent Chlorhydrol, $50 \% \mathrm{w} / \mathrm{w}$ solution, and $0.25 \%$ aluminum chlorhydroxide allantoinate were incorporated in a cream base. The test cream (93) antiperspirant contained

$\%$, weight

A. Cetyl alcohol.............................5.00

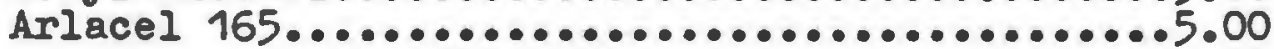

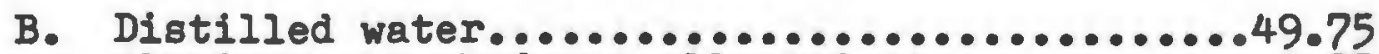

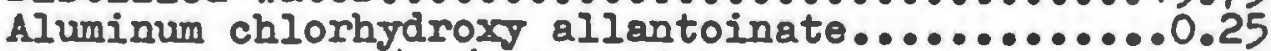
Chlorhydrol, $50 \% \mathrm{w} / \mathrm{w}$ solution..............40.00 100.00

Phase A contained cetyl alcohol for stiffening, consistency, and texture. Arlacel 165 
served both as emulsifier ( This phase was heated slowly with constant stirring to $70^{\circ} \mathrm{C}$. The water phase, B, consisting of suitable concentrations of the active ingredient and the allantoin complex, was heated to $72^{\circ} \mathrm{C}$ to allow for rapid cooling. $B$ was added to $A$ at the same temperature with constant stirring to permit proper emulsification. The emulsion was stirred rapidly until it set at about $40^{\circ} \mathrm{C}$ and then packaged in opaque ointment jars.

This cream was white, Iluffy, easy to apply, and quick-drying. An application of $500 \mathrm{mg}$ of the antiperspirant cream to each axilla provided $100 \mathrm{mg}$ of active ingredient in solution.

The test lotion antiperspirant contained $\%$, weight

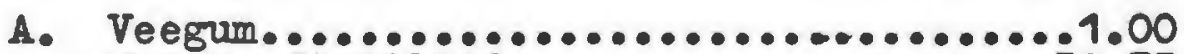

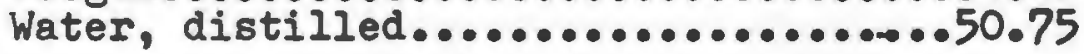

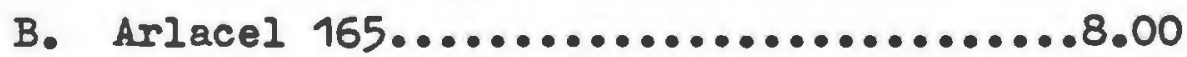

C. Chlorhydrol, 50\% w/w solution........40.00 Aluminum chlorhydrox allantoinate.....0.25

100.00

Veegum was added slowly with continual agitation to water at room temperature until a smooth mixture resulted. The mixture was then heated to $70^{\circ} \mathrm{C}$. Veegum is frequently used in roll-on lotions to increase the viscosity. It also is used as an emulsion stabilizer. Arlacel 165 was heated separately to $75^{\circ} \mathrm{C}$, then added to A with agitation 
and mixed while cooling to $50^{\circ} \mathrm{C}$. The allantoin complex was dissolved in Chlorhydrol, $50 \% \mathrm{w} / \mathrm{w}$ solution at $50^{\circ} \mathrm{C}$ to form a clear solution. This solution was added to the above mixture and mixed constantly until it cooled to $38^{\circ} \mathrm{C}$. This aqueous lotion provided 100 mg of active ingredient in solution per 500 mg of lotion. The cream and lotion both contained Arlacel 165. In the cream, the Arlacel 165 was used to emulsify the oil and water phases, while in the lotion, it was used as a thickener and stabilizer. A trial test showed that the lotion could be applied successfully from a roll-on applicator. This white, viscous, quick-drying antiperspirant was considered the most elegant and cosmetically acceptable vehicle by the volunteers.

Stick formulations introduced a variety of formulation problems. The acidic aluminum salts are not suitable for use in a sodium stearate-based stick. Stearamide, used frequently as an antiperspirant stick building block with great success in industry, was unobtainable. Therefore, a suspensoid stick containing MicroDry, Ultrafine was formulated. A solid stick antiperspirant (97) that was quick-drying and of suitable consistency for axillary application contained 
\%, weight

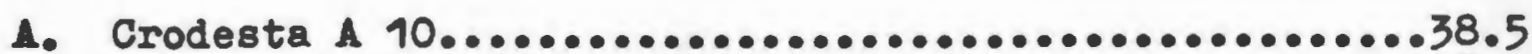

Procetyl AWS...................................9.6



Alcohol soluble aluminum chlorhydroxy allantoinate....0.5

C. Crodamul IPM................................12.9

100.0

Phase A was dissolved at $70^{\circ} \mathrm{C}$ and $B$ was added with constant stirring until a uniform mixture resulted. C was added with constant stirring until uniform. The mixture was poured into 2-gram suppository molds to cool. Crodesta \& 10, the lipophilic gellant, provided excellent structure and slip to a solid stick. Crodamul IPM and Procetyl AWS served as emollients and to reduce tackiness. The latter was also used to improve water dispersability of the antiperspirant agent and act as a dispersing agent for the active ingredient upon application (113). In order to provide a smaller sample application size, a concentration of $38.5 \%$ MicroDry, Ultrafine was necessary. Thus, a solid stick of $260 \mathrm{mg}$ imparted $100 \mathrm{mg}$ of active ingredient. The amount of active ingredient was consistent with the other three dose forms.

Rehydrol is often used by the industry as an antiperspirant agent in pump sprays, because it is effective, quick-drying, and causes a minimum amount of tackiness. It may be used in alcoholic or hydroalcoholic solutions. Stearic acid is generally added to alcoholic solutions 
to prevent gellation and to lubricate the pump spray valve (96). However, to maintain allantoin complex compatibility, a hydroalcoholic solution was needed. So, to maintain consistency in all the vehicles, Chlorbydrol, $50 \% \mathrm{w} / \mathrm{w}$ Bolution was selected as the active ingredient in the alcohol-base dose form. Chlorhydrol is used in many commercial hydroalcoholic solutions $(95,96,98,99)$.

\%, weight



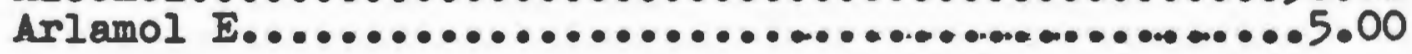

B. Chlorhydrol, $50 \% \mathrm{w} / \mathrm{w}$ solution...................40.00 Alcohol soluble aluminum chlorbydroxy allantoinate..0.25 Water, distilled.

$A$ and $B$ were dissolved separately at room temperature. B was added to A with constant agitation until dissolved. Arlamol E functioned as a solvent, emollient, and valve lubricant. This clear hydroalcoholic test antiperspirant imparted $100 \mathrm{mg}$ of active ingredient per $500 \mathrm{mg}$ of antiperspirant applied. The solution was show to be suitable for use in a commercial manual pump spray.

Perfumes and coloring agents were not incorporated into any of the antiperspirant formulations. This eliminated the possiblitity of allergic reactions, dermatological irritations, physical and chemical formulation incompatibilities, and other variables associated with perfumes and coloring agents. The 
volunteers preferred unscented commercial antiperspirants for their daily use prior to the test.

Preservatives were deemed unnecessary because the ingredients used in formulations are extremely stable. These formulations did not separate, cream, or show any other instability or aging signs during their six-month shelf life.

2. Test procedure. Four vehicles containing aluminum chlorhydrate were compared for efficacy by a well-recognized gravimetric procedure (4-6,9-12,23-27, $38,55,57)$ during a normal work day in each subject's normal work environment.

A detailed report of the proposed project, its objectives, methods, and potential adverse effects was submitted for approval to both a University Human Studies Committee and an Institutional Review Board (Appendix B). Following the guidelines established by these committees, volunteers were asked to maintain normal bathing habits with the exception of an exillary hygiene regimen. The axillary hygiene regimen consisted of abstaining from non-test antiperspirant/deodorant use during the test period, removal of axillary hair with Surgex (a surgical depilatory) three days prior to each sweat collection period, and washing the axillary area with Ivory Soap and water only. Each subject was supplied with the necessary materials by the researcher. 
Sweat was collected on tared adsorbent Webril pads taped anugly to the axillae with Dermicel cloth hypoallergenic tape. Webril pads are made of $100 \%$ soft, lintless cotton. They have no binder and have $\mathrm{pH}$ of 7 . They are used frequently in surgical procedures, plate, press, and camera work, and in gravimetric antiperspirant tests $(6,12,23,24,114)$. \& 4-iply Webril pad was sewn onto a 2-by-4-inch piece of Ziploc. The Ziploc backing ensured the retention of sweat on the pad and easy removal of tape without loss of padding. Each pad was sealed in a Ziploc bag and weighed. All bags were labeled with the subject's name and the axilla and date each pad was to be worn. A detailed calendar of the nine-week experimental protocol and weekly reminders (Appendix C) were distributed to each subject to ensure proper compliance. Six female and two male volunteers, ages 18-34, followed the test guidelines at their own homes and jobs after receiving instructions from the investigator. Subjects were instructed to observe the area outlined by axillary hair. Determining the outline of this region was important, because all future sweat collections and antiperspirants applications were confined to it. The hairy portion of the axilla is the region in which both apocrine and eccrine sweating occur. In a survey of panel and nonpanel persons, the surface area delineated by axillary hair was found to be consistent. 
The calendar was divided into weekly segments. Day 1 of each week was Sundas; dajs 2, 3, 4, 5, 6, and 7 were Monday, Thesday, Wednesday, Thursday, Friday, and Saturday, respectively. On day 4 of the first week, all subjects began the axillary hygiene regimen. On day 7, all subjects removed axillary hair with Surgex, an effective surgical depilatory that removes hair below the skin line (115). Removal of axillary hair is essential to provide a clean, hairless area to collect sweat $(9,23,27,36,55,103)$.

Pretest sweat collections began in week 2 on dajs 4, 5, and 6, using both axillae as controls. At the start of each pretest collection day, the subject washed both axillae with Ivory Soap and water, and patted them dry. The appropriate pad, cotton side to the body, was taped snugly over the clean, dry, delineated axillary area of each axilla. Each panelist secured the tape in a manner most comfortable for him. Most subjects cut the tape into $1 "$ wide strips. The pads were worn throughout a normal day's conditions and environment. After a 10-hour collection period, the tape was removed, and the pads were returned to the designated ziploc bag and sealed. They were collected by the investigator the following morning to be weighed. The difference in weight of the tared Ziploc plus dry pad and Ziploc plus pad following the 10-hour collection period was recorded as the sweat collected. The weight was expressed in milligrams to the nearest tenth of a milligram. 
Pretest sweat data are listed in Table 2.

Pretest sweat ratios were then calculated as

$\frac{\text { Perspiration weight from Right axilla }}{\text { Perspiration weight Irom LeIt axilla }}=$ Perspiration Ratio and averaged (23). Subjects were then paired by similar right to left axillae perspiration ratios (PR). A split plot, 4 by 4, Latin Square experimental design $(116,117)$ was used to eliminate the possibility that a treated heavy- or light-sweating axilla might affect the results. One subject of each pair was treated on his heavy-sweating axilla, while the other subject was treated on his lightsweating axilla. For example the PR, 1.636 of subject $B_{4} D_{2}$ and 1.422 of subject $B_{4} D_{1}$, indicated both subjects sweated more on their right sides. Subject $B_{4} D_{2}$ 's light-sweating or left axilla was chosen randomly as the side to be treated for the duration of the test; therefore, subject $B_{4} D_{1}^{\prime} s$ heavy-sweating or right axilla was treated. Their opposite axillae were assigned as the control. At no time during the test was any antiperspirant applied to the control axillae.

Treatment sweat collections began during week 3 . Test antiperspirants designated for the subject for that week were supplied in tared sealed containers. The two members of a pair applied the same antiperspirant treatment during a given week. The four pairs applied different treatments during a given week conforming to the Latin Square 
TABLE 2

PRETEST SWEAT COILECTION DATA

USED FOR BIOCKING 4 BY 4, SPIIT PIOT, IATIN SQUARE

\begin{tabular}{|c|c|c|c|c|}
\hline \multirow[b]{3}{*}{ Subject } & \multicolumn{3}{|c|}{ Sweat Collection Dates } & \multirow[b]{3}{*}{$\begin{array}{c}\text { Averatte } \\
\text { PR }\end{array}$} \\
\hline & $4-4-28$ & $4-5-78$ & $4-6-78$ & \\
\hline & $\begin{array}{ll}\text { Right } & \text { Left } \\
\text { (mg) } & \text { (mg) } \\
\end{array}$ & $\begin{array}{ll}\text { Right } & \text { lest } \\
\text { (mg) } & \text { (mg) }\end{array}$ & $\begin{array}{ll}\text { Right } & \text { LeIt } \\
\text { (mg) } & \text { (mg) } \\
\end{array}$ & \\
\hline $\mathrm{B}_{1} \mathrm{I}$ & $208.0 \quad 304.0$ & $564.3 \quad 540.3$ & $707.4 \quad 898.5$ & \\
\hline (PR) & 0.684 & 1.044 & 0.787 & 0.838 \\
\hline$B_{1}$ & 115.2116 .2 & $157.4 \quad 231.6$ & 78.1 & \\
\hline PR) & 0.991 & 0.680 & 0.910 & 0.860 \\
\hline & $237.2 \quad 192.2$ & 56.3 & $555.4 \quad 262.2$ & \\
\hline (PR) & 1.234 & 1.647 & 2.118 & 1.666 \\
\hline & $490.5 \quad 293.3$ & $554.0 \quad 236.0$ & 230.3 & \\
\hline (PR) & 1.672 & 2.347 & 2.875 & 2.298 \\
\hline & $1257.4 \quad 1202.1$ & 289.3 & 916.2 & \\
\hline (PR) & 1.046 & 0.968 & 0.945 & 0.986 \\
\hline & $836.0 \quad 630.0$ & $468.1 \quad 710.2$ & 96.5119 .6 & \\
\hline (PR) & 1.327 & 0.659 & 0.807 & 0.931 \\
\hline$B_{4} D_{1}$ & 1742.21614 .2 & $1482.7 \quad 1255.6$ & $1567.2 \quad 781.1$ & \\
\hline (PR) & 1.079 & 1.181 & 2.006 & 1.422 \\
\hline $\mathrm{B}_{4} \mathrm{D}_{2}$ & $520.8 \quad 296.4$ & $1375.6 \quad 970.4$ & $1592.3 \quad 918.2$ & \\
\hline$(\mathrm{PR})$ & 1.757 & 1.418 & 1.734 & 1.636 \\
\hline
\end{tabular}

* PR = Perspiration Ratio = Perspiration weight right axilla 
design (Table 3). The cream was applied directly to the axilla from glassine paper. The stick was applied manually. The lotion and hydroalcoholic solution were applied with tared cotton swabs. All antiperspirants were applied to the designated $2 k_{k}-b y-4 k$-inch axillary area. The antiperspirant application area was larger than the pad area to assure adequate antiperspirant protection in the collection. site (Appendix C).

The axillary hygiene regimen continued in week 3 on days 1 and 2. A measured amount of test antiperspirant was applied to a clean, dry treated axilla. This two-day period was to accommodate the axilla to the antiperspirant (19). No sweat was collected.

On days 3, 4, and 5, antiperspirant was applied to the treated axilla as directed. An elapsed one-minute drying time was allowed before taping the tared pads to the axilla. A tared pad also was taped snugly to the clean, dry, control axilla. The subjects proceeded with their daily routines. At the end of the 10-hour collection period, they removed the tape and sealed the pads in the designated Ziploc. The pads and test antiperspirant containers were collected by the investigator to be weighed for daily sweat weights and amount of antiperspirant applied.

A nine-day period, in which no sweat was collected nor antiperspirant was applied, was allowed for recovery. The axillary hygiene regimen was continued throughout the 
TABIE 3

4 BI 4, SPLIT PLOT, IATIN SQUARE DESIGN

\begin{tabular}{l|l|l|l|l|}
\multicolumn{1}{c}{$C_{1}$} & $C_{2}$ & $C_{3}$ & $C_{4}$ \\
\cline { 2 - 5 }$B_{1} D_{1}$ & $A_{1}$ & $A_{2}$ & $A_{3}$ & $A_{4}$ \\
\cline { 2 - 5 }$B_{2} D_{1}$ & $A_{2}$ & $A_{3}$ & $A_{4}$ & $A_{1}$ \\
\cline { 2 - 5 }$B_{3} D_{1}$ & $A_{3}$ & $A_{4}$ & $A_{1}$ & $A_{2}$ \\
\cline { 2 - 5 }$B_{4} D_{1}$ & $A_{4}$ & $A_{1}$ & $A_{2}$ & $A_{3}$ \\
\hline$B_{1} D_{2}$ & $A_{1}$ & $A_{2}$ & $A_{3}$ & $A_{4}$ \\
\hline$B_{2} D_{2}$ & $A_{2}$ & $A_{3}$ & $A_{4}$ & $A_{1}$ \\
\hline$B_{3} D_{2}$ & $A_{3} D_{2}$ & $A_{4}$ & $A_{1}$ & $A_{2}$ \\
\hline$A_{4}$ & $A_{1}$ & $A_{2}$ & $A_{3}$ \\
\hline & & & & \\
\hline
\end{tabular}

$A=$ Treatments: 1, stick; 2, cream; 3, lotion; 4, hydroalcoholic base

$\mathrm{B}=$ Subject Pairs, 1, 2, 3, 4

$C=$ Weeks, $1,2,3,4$

D = Side Treated: 1, heavy-sweating side; 2 , light-sweating side 
recovery weeks. Recovery periods, weeks 4,6 , and 8 , alternated with treatment weeks 5,7 , and 9, using the test procedure described above for the duration of the experiment.

3. Statistical treatment of results. Post-test sweat collection data were evaluated statistically using the geometric mean of treatment results of a 4 by 4, split plot, Latin Square design $(26,116)$, illustrated in Table 3. The letters $D_{1}$ and $D_{2}$ represent the heavs-sweating sides and light-sweating sides treated, respectively. The columns represent the four treatment weeks, the rows represent subject pairs, and the blocks indicate the treatments. The statistical model describing this treatment design is

$$
\begin{aligned}
y_{j k m p}=\mu & +\alpha_{j}+\beta_{k}+\gamma_{m}+\delta_{p}+(\alpha \delta)_{j p}+(\beta \delta)_{k p}+(\gamma \delta)_{m p} \\
& +\epsilon_{j k m p}
\end{aligned}
$$

where

$$
\begin{aligned}
& J_{\text {jlamp }}=\ln (\text { ratio })=\ln \left(\text { (mg }_{\text {treated }}\right)-\ln \left(\text { Emg }_{\text {control }}\right) \\
& \mu=\text { overall mean } \\
& \alpha_{j}=\text { treatment } j, j=1,2,3,4 ; \varepsilon \alpha_{j}=0 \\
& \beta_{k}=\text { subject } k, k=1,2,3,4 ; \Sigma \beta_{k}=0 \\
& \gamma_{m}=\text { week m, m }=1,2,3,4 ; \sum \gamma_{m}=0 \\
& \delta_{p}=\text { side } p, p=1,2 ; \varepsilon \delta_{p}=0 \\
& \alpha \delta_{j p}=\text { treatment and sides interaction } j p \sim N I D\left(0, \sigma^{2}\right) \\
& \beta \delta_{\mathrm{kp}}=\text { subject and sides interaction } \mathrm{kp} \sim \mathrm{NID}\left(0, \bar{\sigma}^{2}\right)
\end{aligned}
$$


$\gamma \delta_{\text {mp }}=$ weeks and sides interaction mp $\sim \mathbb{N I D}\left(0, \sigma^{2}\right)$

$\epsilon_{\text {jomp }}=$ error for treatment $\mathrm{j}$, subject $k$, week $\mathrm{m}$, side $p \sim N D D\left(0, \sigma^{2}\right)$

The $10 \mathrm{~V}$ is illustrated in Table 4.

The sweat ratios were calculated as

$$
\text { In }(\bar{z} / \bar{x})=\text { In }\left(y_{1}+y_{2}+y_{3} / x_{1}+x_{2}+x_{3}\right)
$$

where $J$ - perspiration weight (mg) of the treatod alde vind $x=$ perspiration weight (ng) of the control side. The post-test sweat ratios were transformed to natural logarithms to simplify the calculations in the analysis of variance table. The $\mathrm{F}$ test indicated the absence or presence of significant differences in the variables.

The ratio of treatment axilla to control axilla was estimated by

$$
\ln \hat{R}_{j}=\Lambda_{j} / 8
$$

therefore

$$
\hat{\mathrm{R}}_{\mathrm{j}}=\boldsymbol{\theta}^{\left(A_{j} / 8\right)}
$$

where $\hat{\mathrm{R}}_{\mathrm{f}}$ is the post-test treatment ratio mean.

The antilog of the geometric mean of the data from each treatment was calculated and subtracted from unity to obtain the percent sweat reduction of each treatment.

$\left(1-\hat{\mathbf{R}}_{\mathfrak{j}}\right) \times 100$ = percent sweat reduction.

Confidence intervals of $95 \%$ about the treatment mean, 
TABLE 4

ANALYSIS OF VARIANCE FOR 4 BY 4, SPLIT PLOT, LATIN SQUARE

\begin{tabular}{|c|c|c|c|c|}
\hline Source of Variation & $\mathrm{DF}$ & ss & MS & F Test \\
\hline Treatments (A) & 3 & $\sum_{j} A_{j}^{2} / 8-G^{2} / 32$ & $\mathrm{Ss}_{\mathrm{A}} / 3$ & $\operatorname{MS}_{\Lambda} /$ error (A) \\
\hline Subject Pairs (B) & 3 & $\left\langle B_{k}^{2} / 8-G^{2} / 32\right.$ & $\mathrm{SS}_{\mathrm{B}} / 3$ & $\mathrm{MS}_{\mathrm{B}} / \operatorname{error}(\mathrm{A})$ \\
\hline Weeks (C) & 3 & $\leqslant C_{m}^{2} / 8-G^{2} / 32$ & $\mathrm{ss}_{\mathrm{C}} / 3$ & $\mathrm{MS}_{C}$ /error (A) \\
\hline Sides (D) & 1 & $\sum_{p} D_{p}^{2} / 16-G^{2} / 32$ & $\operatorname{ss}_{D} / 1$ & $\mathrm{MS}_{\mathrm{D}}$ /error (B) \\
\hline$\underset{(B D)}{\text { Subjects } x \text { Sides }}$ & 3 & $\sum_{k p}\left\{\left(B D_{k p}\right)^{2} / 4-S S_{B}-s S_{D}-G^{2} / 32\right.$ & $\mathrm{Ss}_{\mathrm{BD}} / 3$ & $\mathrm{MS}_{\mathrm{BD}}$ /error (B) \\
\hline Weeks $x$ Sides & 3 & $\sum_{m p} \varepsilon\left(C D_{m p}\right)^{2} / 4-S S_{C}-S S_{D}-G^{2} / 32$ & $\mathrm{ss}_{\mathrm{CD}} / 3$ & $\mathrm{MS}_{\mathrm{CD}}$ /error (B) \\
\hline
\end{tabular}


TABLE 4-Continued

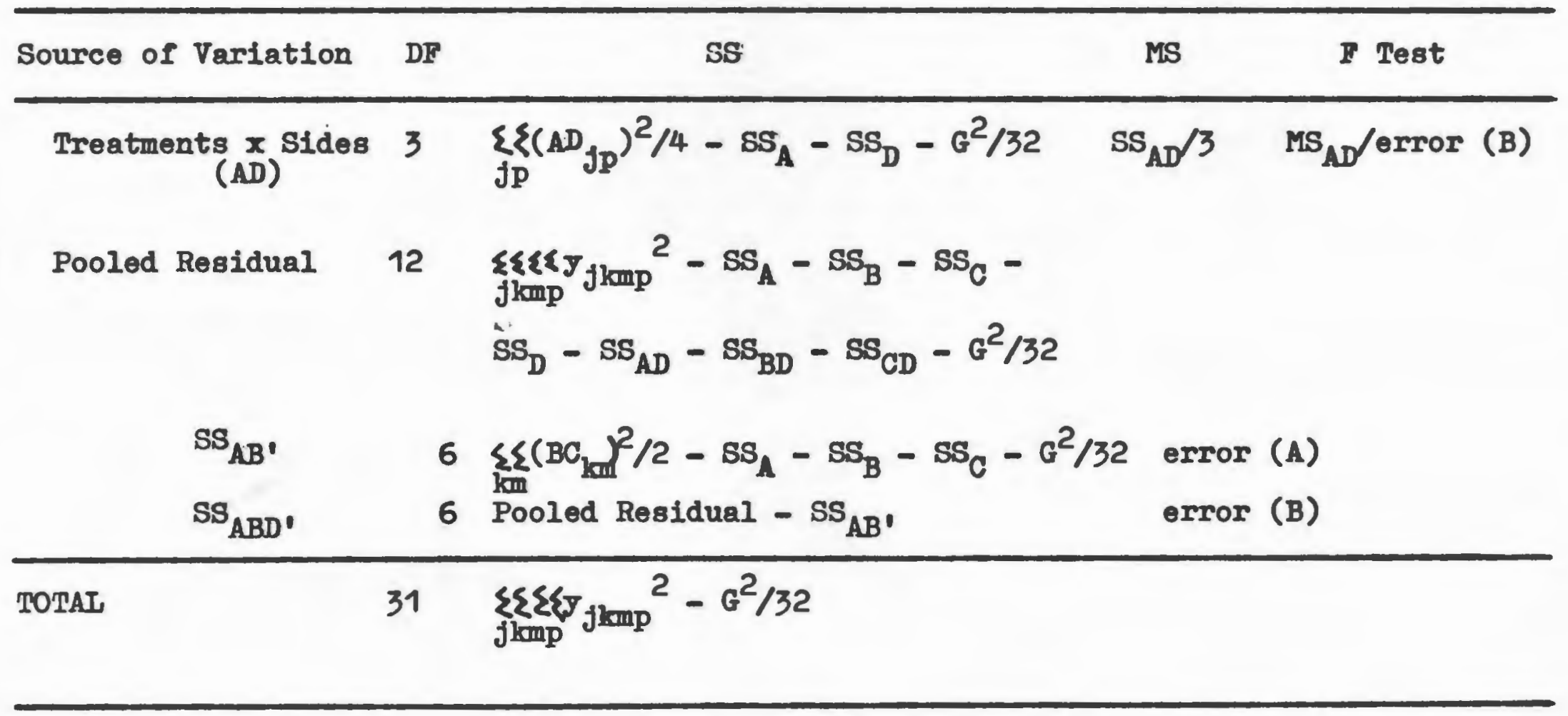


$\hat{\mathrm{R}}_{\mathrm{f}}$, were estimated by

$$
\left(\Lambda_{j} / 8\right) \pm t_{6 ; 05} \sqrt{\frac{\operatorname{error}(\Lambda)}{8}}
$$

The upper and lower confidence limits were expressed in terms of percent sweat reduction by

$$
\left(1-e^{u}\right) \times 100
$$

and

$$
\left(1-e^{1}\right) \times 100
$$

where $e^{u}$ and $e^{l}$ are the antilogs of the upper and lower confidence limits, respectively.

Having shown significant treatment differences with the F test, the Least Significant Difference (ISD) test was performed to make individual comparisons of differences between pairs of treatments.

$$
\left|\bar{x}_{i}-\bar{x}_{j}\right| \geq I S D
$$

where $\bar{x}_{i}, \bar{x}_{j}=$ treatment means.

$$
\operatorname{LSD}_{95}=t_{6, .05} \sqrt{\frac{2(\operatorname{error}(A))}{8}}
$$




\section{DISCUSSION AND RESULTS}

The tests were organized so that there was a two-week abstinence from antiperspirant use before the treatment sweat collections began. Subjects abstained from antiperspirant use for one week before the three pretest sweat collection readings were made. There was a one-week recovery period of no antiperspirant use between treatments. Abstinence from antiperspirants ensured no carry-over effect from previous antiperspirant use. All eight subjects collected sweat for three collection days per treatment. All subjects were tested on all four treatments.

The F test (Table 5) indicates differences in treatment effects, sides by subjects effects, and weeks by sides effects. No significant differences were found in subjects, weeks, sides or treatments by sides.

It is of particular interest that the sides' (D) F value was extremely low. The pretest blocking procedure was instituted to account for the light- or heavysweating side treated, jet the results indicated that the side which was treated could have been randomly selected without regard to pretest sweat ratios. This is in agreement with Wooding and Finklestein's (26) decision to eliminate pretest sweat ratios in evaluating antiperspirant efficacy. This result is further substantiated by the 
TABLE 5

ANOVA OF POST-TEST DATA

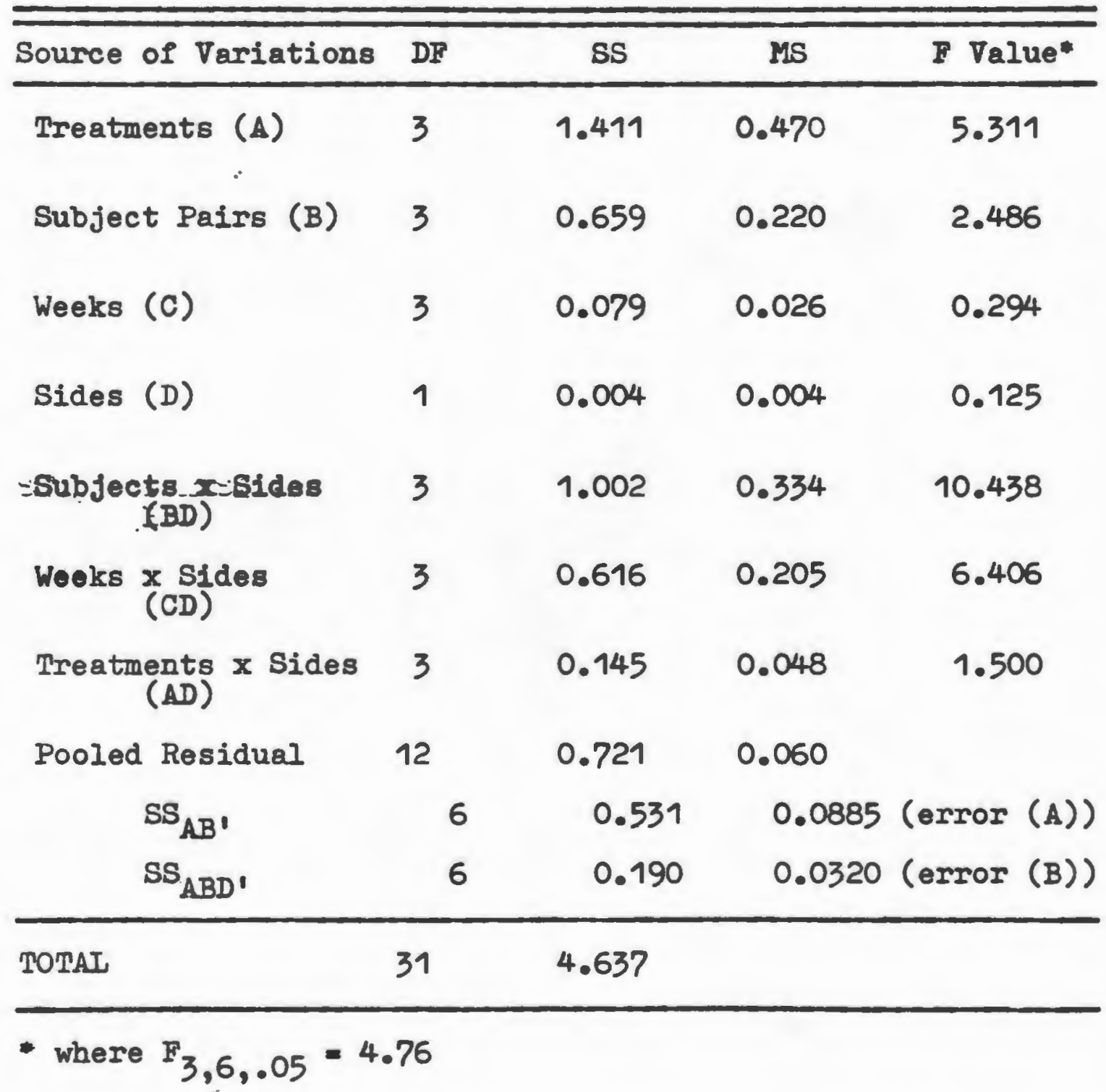


insignificant $F$ value of subject pairs (B). Subjects were paired by similar pretest treatment ratios. One subject was treated on his heavy-sweating side, while his paired opposite was treated on his light-sweating side. Subject pair 3 had pretest sweat ratios very close to unity (Table 2) in which case it was an arbitrary decision to call a side light- or heavy-sweating. Treatment by sides effects (AD)" indicates that the side to which the treatment is applied is not significant.

However, the $F$ value indicates a strong subjects by sides (BD) effect. Figure 3 gives an indication of why this difference occurred. By plotting the light side to heavy side pretest sweat ratio average of each subject pair, versus the sum of the treatment ratios' natural logarithms of each subject by side (BD), the cause of the interaction is readily observable. All subject pairs exhibited similar sides by subfects effects, except subject pair 3. This interaction is of particular interest because they had pretest sweat ratios close to unity. Their daily pretest sweat ratios showed extreme day-to-day variations, but averaged close to unity. Steed (9) also observed marked variations in subjects with pretest ratios close to unity. Otherwise, the other three subject pairs had no difference in this effect.

As expected, there was no significant difference in treatment weeks effects (C). During each of the four 
$\sum_{k p}^{\sum\left(B D_{k p}\right)}$

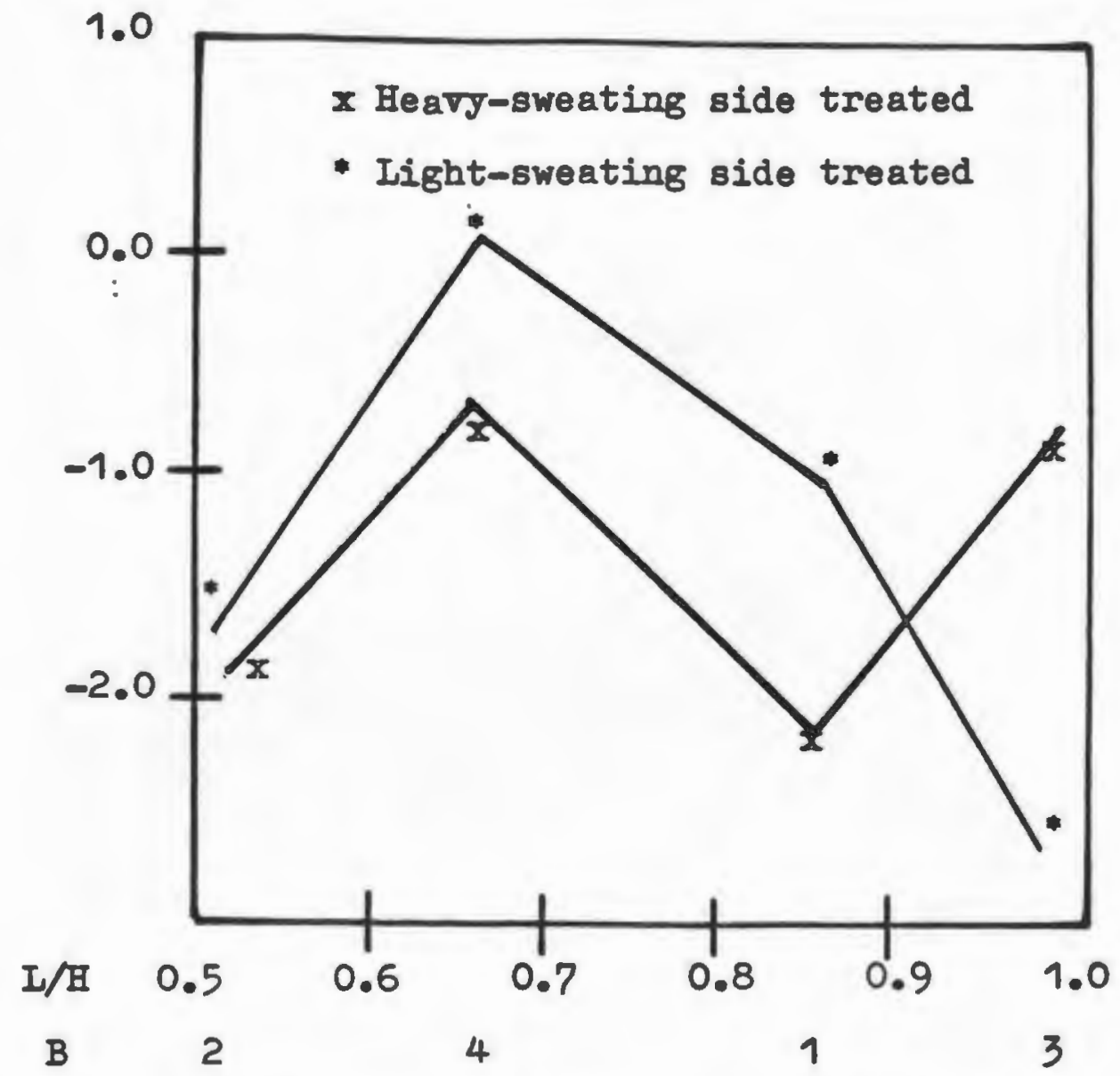

Figure 3. The pretest sweat ratios of lightsweating side to heary-sweating side ( $\mathrm{L} / \mathrm{H}$ ). of Subject Pairs (B) versus Subjects by Sides $\left(\sum\left\{\left(B D_{k p}\right)\right)\right.$ illustrates the Subjects by Sides interaction occurs in Subject Pair 3. 
58

treatment weoks, all four treatments were tested, with each subject pair testing a different treatment in a given week, and no pair testing the same treatment in the same week. There was no major change in the sum of the ratio's natural logarithms for each treatment week $\left(\leqslant C_{m}\right)$, despite the fact that during the first three treatment weeks the average environmental temperature was in the low 60sp) and the average relative humidity was $40 \%$, while in treatment week 4, the average temperature was in the high 70s? and the average relative humidity was $70 \%$ (118). Most subjects were wearing lightweight sweaters during this period and working indoors. However, weeks by sides (CD) exchibited a significant difference. Figure 4 plots the treatment week versus the sum of each treatment week by side ( $\left.\sum \varepsilon C D_{m p}\right)$. Heavg- versus light-side treatment shows a major change during week 3. Since this does not appear to be due to environmental factors, it may well have been caused by emotional factors. Treatment week 3, May 7, occurred during the last week of classes or examination periods for the subjects, who were all in academic surroundings. There was a great deal of pressure on the subjects to finish course work and write exams. Fmotional sweating has been suggested as a cause of erratic sweat ratios and rates $(57,58)$. However, it did not affect the antiperspirants' effectiveness. All subjects participated in muscular exercise, such as tennis, jogging, or dancing, 
$\sum_{m p}\left(C D_{m p}\right)$

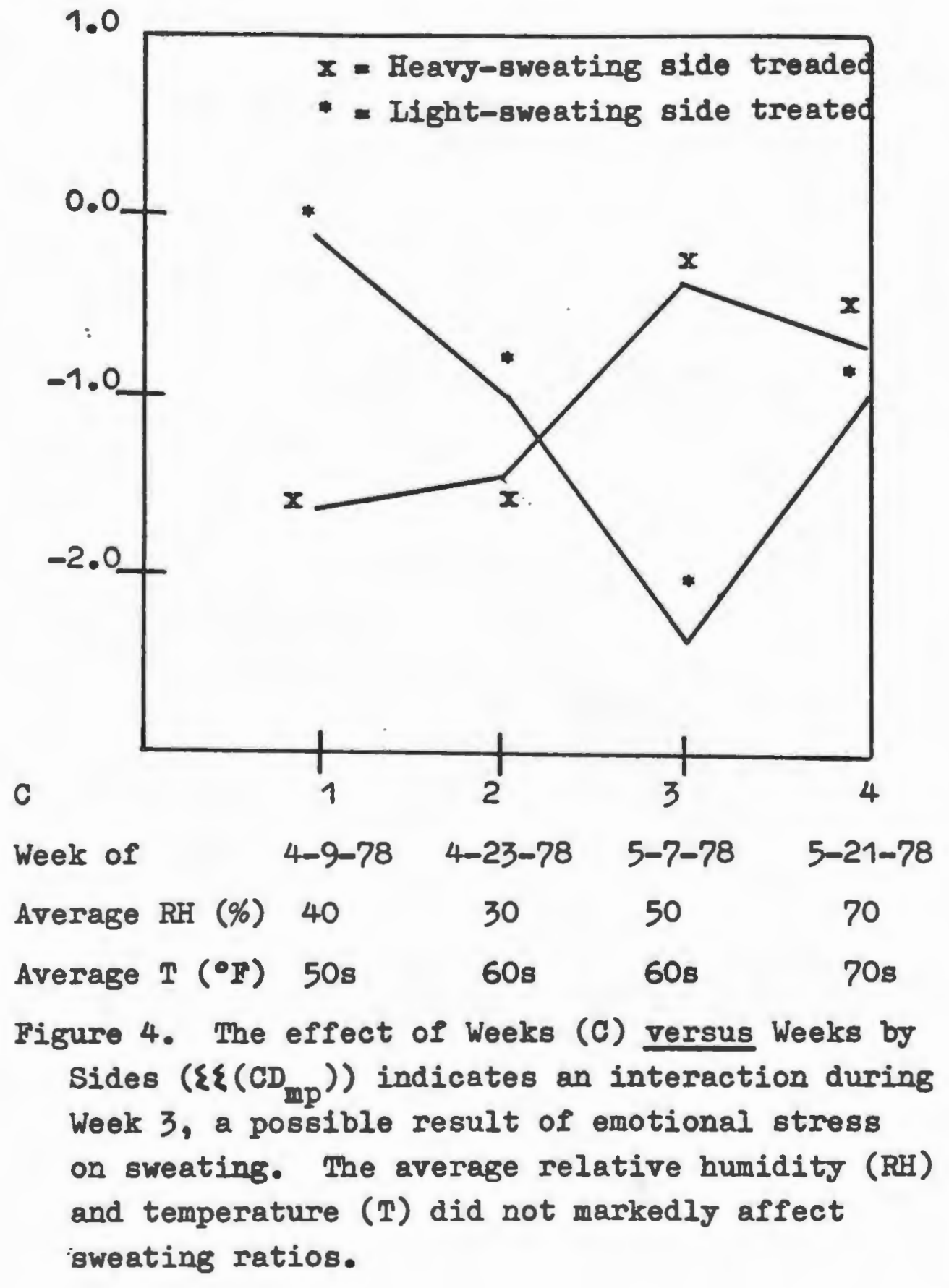


60

at various times. This activity was noticeable in daily sweat collection weights, but not in overall sweat ratios. Antiperspirant effectiveness was maintained during exercise.

A significant difference in treatments was caused by the stick antiperspirant. The natural logarithms of the treatment means ( In $\hat{\mathrm{R}}_{\mathrm{j}}$ ) in Table 6 showed a marked difference in treatment 1 's mean compared to the other three treatment means. This is verified by the ISD test. However, no significant difference was found among treatments 2, 3, and 4 .

Percent sweat reduction results in decreasing order of antiperspirant effectiveness response are treatments 3 (lotion, 38.0\%), 4 (hydroalcoholic solution, 32.4\%), 2 (cream, 31.8\%), and 1 (stick, $-6.2 \%$ ). Percent sweat reductions and their confidence intervals are shown in Table 6. The wide confidence intervals, a result of a low degree of freedom and high standard deviation (error (A)), are not uncommon in antiperspirant efficacy testing at normal temperatures $(9,57)$. However, percent sweat reduction results of the treatments containing Chlorhydrol, $50 \% \mathrm{w} / \mathrm{w}$ solution, agreed with previous studies $(4,9,19,96,108)$. The previous studies showed sweat reduction averaged $30-40 \%$, regardless of concentrations of antiperspirant agent applied. Table 6 lists the average dose of active antiperspirant agent applied. $I_{t}$ is curious to note that the lotion with the lowest dose applied obtained 
TABLE 6

ANTIPERSPIRANT TREATMENT EPFICACY AND DOSAGE

\begin{tabular}{cccccc}
\hline \hline & $\begin{array}{c}\text { Percent } \\
\text { Sweat } \\
\text { Reduction } \\
(\%)\end{array}$ & $\begin{array}{c}\text { Confidence } \\
\text { Intervals, } \\
95 \% \\
(\%)\end{array}$ & $\begin{array}{c}\text { Average } \\
\text { Treatment } \\
\text { Applied } \\
(\mathrm{mg})\end{array}$ & $\begin{array}{c}\text { Average Dose } \\
\text { Active Agent } \\
\text { Applied } \\
\text { (mg) }\end{array}$ \\
\hline $\mathrm{A}_{1}$ & 0.060 & -6.2 & -37.3 to 17.9 & 143.04 & 69.16 \\
$\mathrm{~A}_{2}$ & -0.382 & 31.8 & 11.8 to 47.2 & 379.96 & 75.99 \\
$\mathrm{~A}_{3}$ & -0.478 & 38.0 & 19.8 to 52.0 & 172.76 & 34.55 \\
$\mathrm{~A}_{4}$ & -0.391 & 32.4 & 12.5 to 47.7 & 263.52 & 52.70 \\
\hline
\end{tabular}

$a_{A_{1}}$, stick; $A_{2}$, cream; $A_{3}$, lotion; $A_{4}$, hydroalcoholic solution.

$\mathrm{b}_{\mathrm{R}_{\text {atio }}}$ of treated axilla to control axilla estimated by $\ln \hat{\mathrm{R}}_{\mathrm{J}}=\mathrm{A}_{\mathrm{J}} / 8$. 
the best antiperspirant efficacy results, while the stick with a high dose of active ingredient applied increased sweating on the treated side. Subjects generally applied the same amount of a given antiperspirant during the treatment week. Individual subjects tended also to be consistent in the application of a small or large amount of antiperspirant throughout the test. Since subjects applied the treatments themselves, this may be a result of personal preference for commercial antiperspirant quantities used routinely before engaging in this experiment.

Personal acceptance of a product frequently plays an important role in the effectiveness of a product $(11,64,96)$. The lotion was considered the most cosmetically acceptable and elegant dose form by all subjects, while the stick form brought many complaints. The subjects used commercial aerosols or roll-on antiperspirant/deodorant products prior to testing. None of the subjects had ever used a stick or cream-based antiperspirant before. This may also have influenced their acceptance or rejection of the vehicles.

A small scale test was conducted by one subject using only the stick vehicle minus the active ingredient. This subject followed the same protocol used during the test weeks. The average sweat ratio was close to unity. Daily ratios also were close to unity. Since the subject's heavy-sweating side was treated and a decrease in sweat on 
the treated side was observed, the base was ruled out as a properspirant. Of course, ratios close to unity, as noted previously in subject pair 3, produced erratic results. Increased sweat ratios with the stick formulation may have been caused by the antiperspirant agent being suspended in the vehicle coupled with difficulty in application.

The antiperspirant agent was in suspension in the stick formula, rather than in solution as in the other three treatments (95-97). The activity of MicroDry, Ultrafine was dependent on the dispersing agent, Procetyl AWS. The activity of topically applied drugs is often influenced by their release rates of drugs from the carrier vehicle (1-10, 91).

The incorporation of MicroDry, Ultrafine into the stick base resulted in a hardening, caused by the suspension and the dry, impalpable powder in the base, so that the product was heavier and more difficult to apply than the vehicle alone.

Day-to-day sweat ratios vary, although the heavysweating side usually remains the same. It is of particular interest to note that, when the same amount of active ingredient was applied to a given subject during a given treatment week, the sweat ratios still varied from day-to-day, but did not affect overall antiperspirant efficacy. This daily fluctuation in sweat ratios was the reason for considering all collection data, regardless 
of a day of light or heavy sweating. Sweat collection data of all participants were used whether they sweat profusely or sparingly. These data reflect a normal population that makes use of antiperspirants in the daily environment.

The effect of dominant-handedness on sweat ratios could not be assessed conclusively. Of eight subjects, four sweat more on the right axilla, but one of these four was left-handed. Two subjects had sweat ratios close to unity. Their heavy-sweating sides were on the left. Both these subjects were right-handed. Of the two subjects with a heavier sweating left axilla, one was right-handed and the other was left-handed.

The males, who removed their axillary hair for the first time, noted a marked decrease in: axillary odor $(36,38$, $54,55)$ and developed an immediate dermatitis-like reaction following the first application of Surgex. This reaction disappeared within 24 hours without medical treatment. It did not recur in subsequent applications. The females did not complain of irritation from Surgex. The daily sweat volume of the majority of females was greater than that of the two male subjects.

Aside from discomforture experienced with the stick form, no complaints of irritation from antiperspirant test products were recorded. The incorporation of allantoin complex in combination with aluminum chlorhydrate was apparently beneficial in reducing antiperspirant irritant 
potential and enhancing cosmetic qualities of the dose form. However, the use of the cloth hypoallergenic tape became uncomfortable by the third collection day. This did not appear to affect sweat weights or ratios. Exercise and emotional stress had the greatest effect on sweat weights.

\section{Future Studies}

1. Antiperspirant efficacy could be tested in individuals who exhibit sweat ratios close to unity. The same test could be conducted on subject pair 3 with reversed sides treated to see if the same interaction would occur and how unity ratios affect sweating.

2. Studies could be designed to test varying concentrations of the same agents in the same vehicle and in different vehicles.

3. A detailed study could be conducted of antiperspirant release rates from various vehicles, especially a solution versus a suspension. Further studies are needed of the stick vehicle only compared to the stick antiperspirant and how individual vehicular components affect the active ingredient's release rate.

4. This study could be repeated exactly as presented here, using the same subjects and having them each apply identical amounts of active ingredient to the axilla, then comparing results in ordinary and controlled environments. 


\section{CONCLUSIONS}

1. It is concluded that vehicle does not affect antiperspirant efficacy.

2. However, release rate of the active ingredient from the vehicle plays an important role in antiperspirant efficacy, as observed with aluminum chlorhydrate in solution in the cream base, aqueous lotion, and hydroalcoholic base versus aluminum chlorhydrate in suspension in the solid stick.

3. Antiperspirant treatment response in terms of percent sweat reduction (in decreasing order of effectiveness) was: lotion, $38.0 \%$; hydroalcoholic solution, $32.4 \%$; cream, $31.8 \%$, and stick, $-6.2 \%$. The gravimetric testing procedure conducted during a normal work day in each subject's normal work environment produced percent sweat reduction results well within the acceptable antiperspirant efficiency ranges.

4. The 4 by 4 , split plot, Latin Square experimental design was statistically satisfactory. Statistical analysis indicated that the side treated may be selected randomly without compromising the results.

5. Sweat weights may be affected by temperature, muscular exercise, or emotional stress. However, these factors did not affect antiperspirant efficiency. 


\section{APPENDICES}

\section{APPENDIX A}

Several preliminary formulations were tested and compared for physical and chemical compatibility, stability, and cosmetic elegance and acceptability. Physical and chemical compatibility results led to the selection of aluminum chlorhydrate over modified aluminum chlorhydroxy allantoinate as the active agent. Aluminum chlorhydroxy allantoinate in concentrations of $0.25 \%$ was added to formulations containing aluminum chlorhydrate for its therapeutic and cosmetic properties. The formulations listed below are examples of preliminary formulations tested. Several additional preparations based on the listed formulas were formulated by varying the concentrations of certain component ingredients to aid in the selection of the test antiperspirant products.

The following product is an example of a basic oil-in-water emulsion (90). It was a well-textured cream; however, it was stiff and dry on application.

$\%$, weight

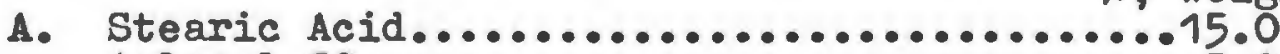

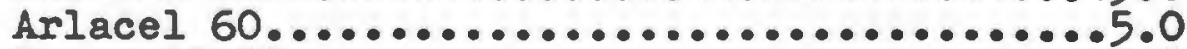

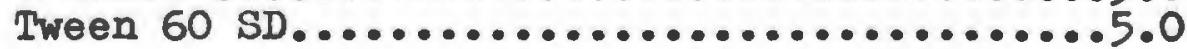

B. Distilled water......................55.0 
C. Aluminum chlorhydroxy

i allantoinate modified.................20.0

100.0

Preparation: Heat A and B separately to $85^{\circ} \mathrm{C}$. Add B to $A$ with constant agitation until cooled to $45^{\circ} \mathrm{C}$. Add C. Stir until a smooth mixture is formed.

This product (90) was a smooth, homogenous, fluffy, cosmetically appealing cream. It deposited a fine, white, quick-drying film upon application.

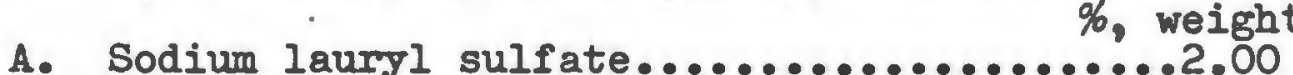
Distilled water......................15.00

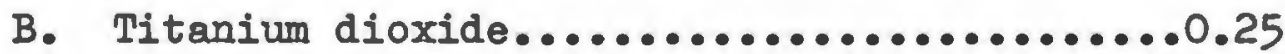

C. Aluminum chlorhydroxy

allantoinate modified................15.00

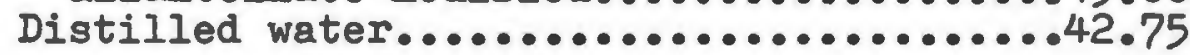

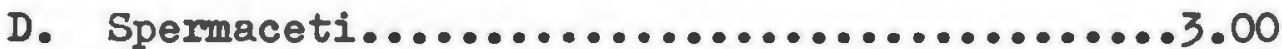

Glyceryl monostearate................16.00

Myri 52............................6.00

$$
100.00
$$

Preparation: Stir A until dissolved. Suspend B in $A$, warm to $70^{\circ} \mathrm{C}$. Stir C. until dissolved and warm to $70^{\circ} \mathrm{C}$. Heat D slowly with constant agitation to $65^{\circ} \mathrm{C}$. Run $D$ into mixture $A B$ while stirring. Slowly add $C$ at $60^{\circ} \mathrm{C}$. Stir constantly to $40^{\circ} \mathrm{C}$.

This stiff, cosmetically undersirable cream contained

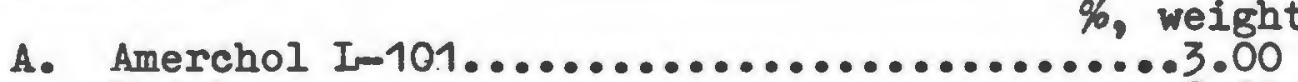

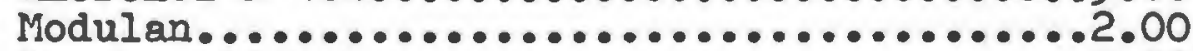

Spermaceti..........................4.00

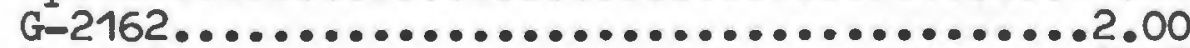

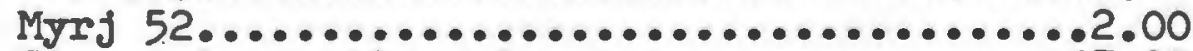

Glyceryl monostearate................17.00

B. Propylene glycol........................3.00

Distilled water.......................27.75 
C. Chlorhydrol, 50\% w/w solution............38.00 Aluminum chlorhydroxy allantoinate.........0.25 Titanium dioxide.......................1.00

$$
100.00
$$

Preparation: Heat A and B separately with constant stirring to $85^{\circ} \mathrm{C}$. Add B to A slowly, stirring constantly to $40^{\circ} \mathrm{C}$. Add $\mathrm{C}$ to mixture and stir to $35^{\circ} \mathrm{C}$.

A cosmetically elegant cream that was easy to apply was formulated (94). However, the desirability of limiting the number of component ingredients in the test procedure eliminated this formula.

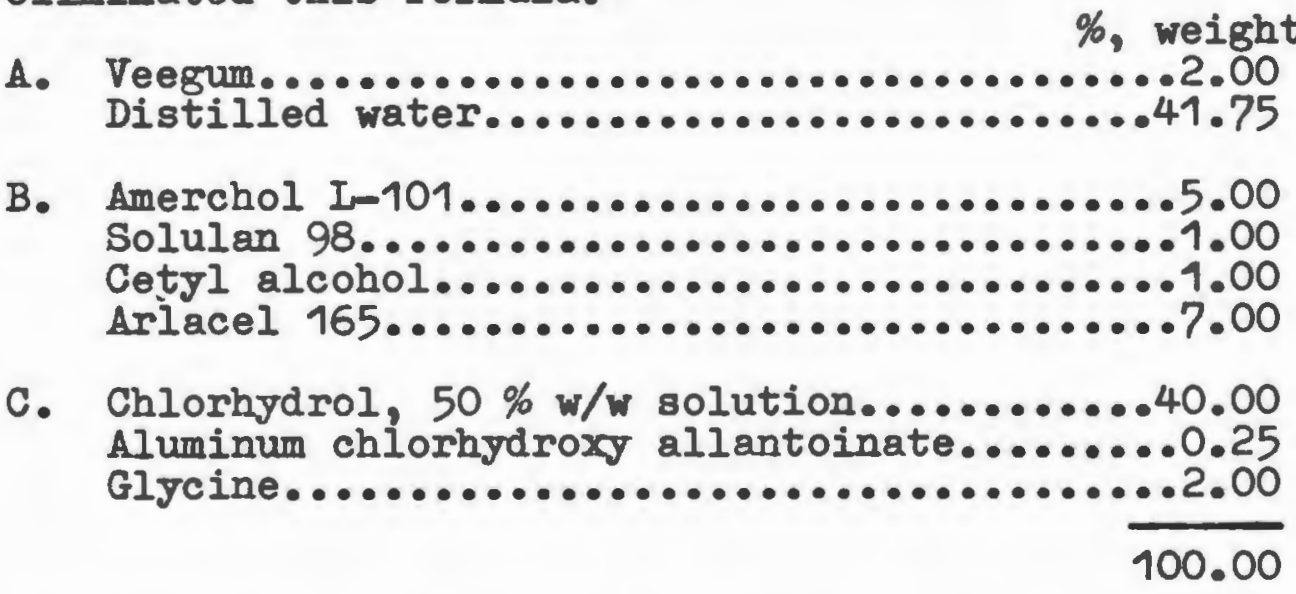

Preparation: Add Veegum to water slowly, agitating until smooth. Heat to $80^{\circ} \mathrm{C}$. Heat B to $70^{\circ} \mathrm{C}$. Add B and A stirring constantly. Cool to $35^{\circ} \mathrm{C}$. Mix C at room temperature until a clear solution is formed. Add $C$ to mixture $A B$. Continue stirring until a smooth, homogeneous cream is formed.

An extremely viscous oil-in-water lotion emulsion was prepared (94). The consistency was suitable for roll-on application; however, a simple aqueous lotion was preferred as a test vehicle.
A. Amerchol I-101.
$\%$, weight
Solutan 98
Cetyl alcohol..........................1.00

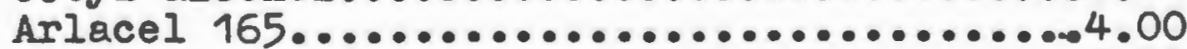
Glycerine............................00 


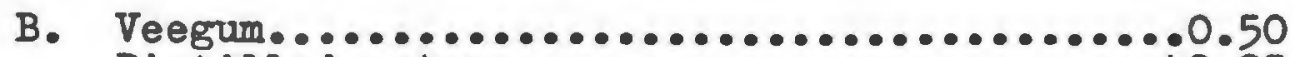

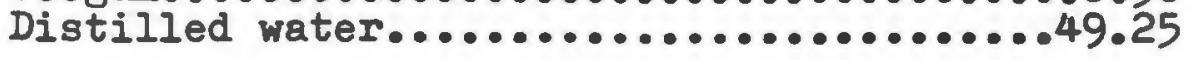

C. Chlorhydrol, 50\% w/w solution............36.00 Aluminum chlorhydroxy allantoinate.........0.25

100.00

Preparation: Disperse Veegum thoroughly in water at poom temperature. Heat to $90^{\circ} \mathrm{C}$ and hold at this temperature while stirring for one hour. Heat $A$ to $80^{\circ} \mathrm{C}$. Add $B$ to A slowly with constant stirring. Stir to $40^{\circ} \mathrm{C}$. Add C. Continue stirring to $35^{\circ} \mathrm{C}$.

The following two formulas (99) are examples of the solubility difficulties encountered in preparing an alcohol-based antiperspirant with the alcohol soluble form of modified aluminum chlorhydroxy allantoinate.

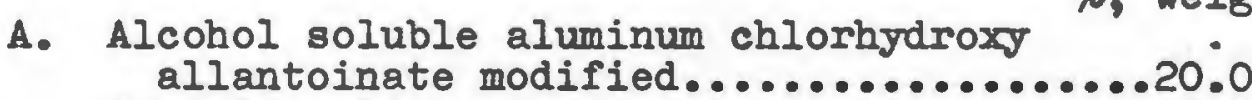
$\%$, weight

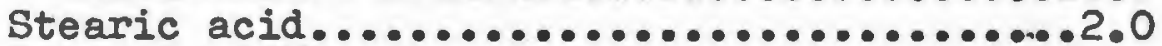

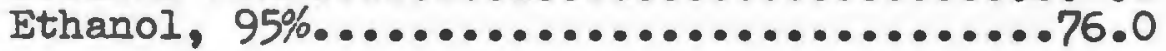

B. Arlamol E............................. 100.0

Preparation: Dissolve A at room temperature. Add B, stirring until a clear solution is formed.

A. Ethanol, $95 \% \ldots \ldots \ldots \ldots \ldots \ldots \ldots \ldots \ldots$, weight

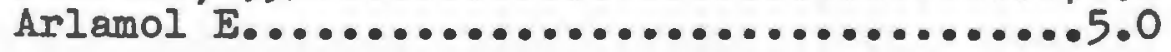

B. Alcohol soluble aluminum chlorhydroxy

allantoinate modified..................20.0

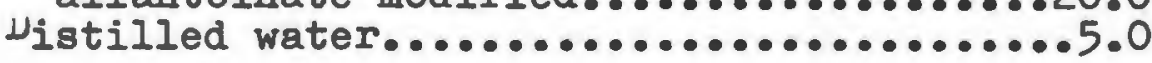

Preparation: Stir A at room temperature until a clear solution is formed. Slowly add B and stir until clear.

This quick-drying, nontacky solution was formulated employing a concentration of Rehydrol equivalent to doses af aluminum chlorhydrate in the test products (99). 


$$
\% \text {, weight }
$$

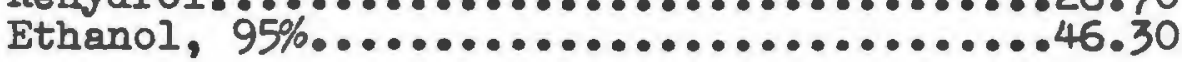

B. Distilled water.....................24.75

Alcohol soluble aluminum chlorhydroxy

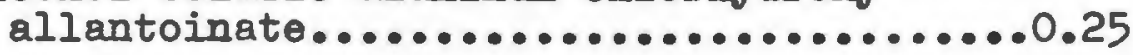

C. Arlamol E...........................2.00

$$
100.00
$$

Preparation: Dissolve separately A and B. Add C to A. Stir until a clear solution is formed. Add B. Stir until clear.

The acidic aluminum salts are not suitable for use in a sodium stearate-based stick. Sodium aluminum chlorhydroxy lactate, forms a cosmetically acceptable, jet ineffective soap-based antiperspirant stick. The neutral gelling agent, Crodesta 10 , produces a stick of suitable consistency. The addition of silicone fluid reduces tackiness and enhances stick slip and structure. However, the following formula (97) crumbled upon application.

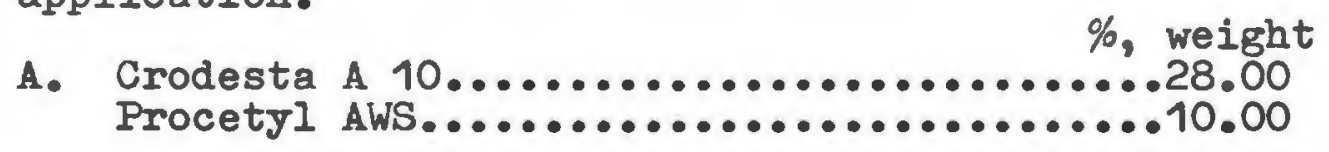

B. Rehydrol............................20.00 Alcohol soluble aluminum chlorhydroxy

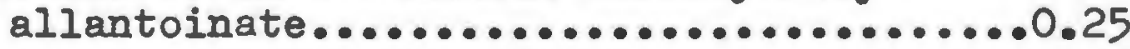

C. Silicone Fluid 200, 1000cps...........41.75 $\frac{100.00}{10 . \ldots 1}$

Preparation: Heat A to $65^{\circ} \mathrm{C}$. Add B. Stir until uniform. Add C. Stir until smooth. Pour into 2-gram suppository molds to cool.

The following water-in-oil emulsion stick (97) 
was cosmetically unacceptable. The stick was dry and tacky upon application. The excessive number of component ingredients, and the emulsion base, were additional reasons to eliminate: this product.
A. Veegum $\%$, weight

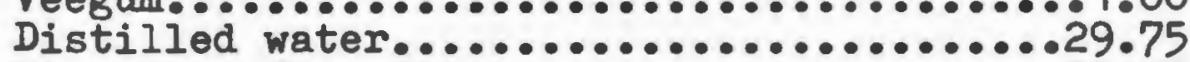

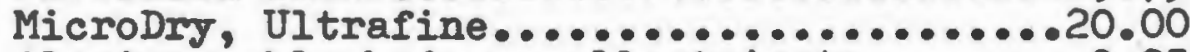
Aluminum chlorhydroxy allantoinate........0.25

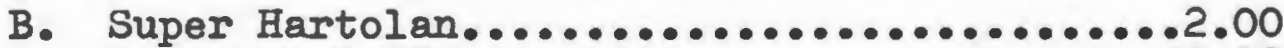

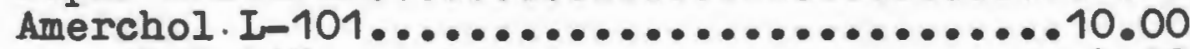

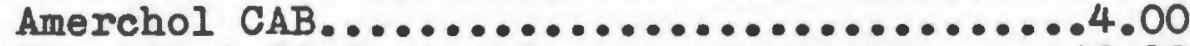

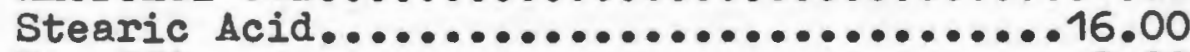

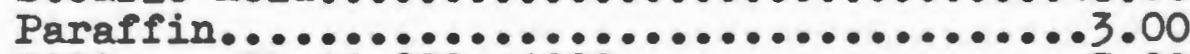

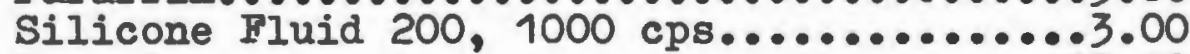

Propylene glycol......................10.00

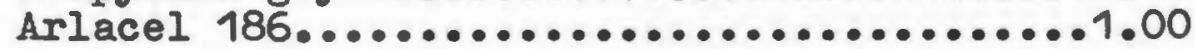

$$
100.00
$$

Preparation: Disperse the Veegum in water. Add " . the MicroDry and allantoin complex. Heat A with constant stirring to $85^{\circ} \mathrm{C}$. Heat $B$ with constant stirring to $85^{\circ} \mathrm{C}$. Add $A$ to $B$ and blend until smooth. Pour into 2-gram suppository molds to cool.

The stick antiperspirant formula was adapted from

a lipstick base. The stick's consistency was cosmetically undesirable.for antiperspirant application. (92).
A. Ozokerite.
$\%$, weight
Carnauba

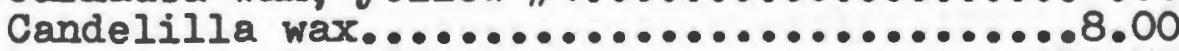
Propylene glycol.....................51.35
Tenox BHT.

B. Crodamul IPM.........................10.30

C. MicroDry, Ultrafine...................20.00

Aluminum chlorhydroxy allantoinate...........25

$$
100.00
$$

Preparation: Heat A to $90^{\circ} \mathrm{C}$ with constant stirring. Add B, stirring until smooth. Add C, stirring until smooth. Pour into 2-gram suppository molds to cool. 


\section{APPENDIX B}

\section{Experimental Protocol}

The Effect of Vehicle on Antiperspirant Efficacy College of Pharmacy, University of Rhode Island, 1978

Investigators:

M. H. Smith, B.S.

Graduate Student

J. M. Lausier, Ph.D.

Associate Professor, Department of Pharmacy

G. E. Osborne, Ph.D.

Professor, Department of Pharmacy

C. T. Rhodes, Ph.D.

Chairman and Professor, Department of Pharmacy

C. I. Smith, Ph.D.

Chairman and Professor, Department of Medicinal Chemistry

Objectives: This study is concerned with how

vehicular excipients in an antiperspirant formulation affect the efficacy of the product. Using a single, proven antiperspirant entity in different vehicles, we shall examine the effect of those vehicles on the efficacy of typical cosmetic products. A roll-on lotion, a cream base, a solid stick, and an alcohol base such as one used in the manual pump spray will be formulated and evaluated gravimetrically for the influence of vehicle on antiperspirant efficiency. 
Preliminary Screening of Subjects: Subjects considered for this study will be healthy persons itth no broken or irritated axillary skin and no sensitivities to Aluminum Chlorhydrate, Aluminum Chlorhydroxy Allantoinate, or thioglycollates. Subjects will undergo sample patch tests several days prior to testing to check for sensitivities, toxicity, and irritation that may result from the antiperspirant products or the hair-remover cream. Ang medical or cosmetic abnormality which the investigators believe may be likely to complicate the study will exclude the subject.

All subjects will be interviewed carefully and pertinent medical, especially dermatological, information will be gathered. Investigators will explain the informed consent form to all participants. All participants will have read the informed consent form before they will be allowed to sign it. Participants will be able to question the investigators. Any subjects may withdraw from the study at any time during the investigation.

Participants will be required to abstain from non-test antiperspirant/deodorant use during the test period, remove axillary hair with a surgical depilatory at designated intervals during the test period, and wash the axillary area with Ivory Soap and water only.

The test will be conducted during a normal work day for 10 hours in the subject's normal work environment. Results will be evaluated statistically using a gravimetric 
technique.

Each subject will be supplied with Surgex, a hair-remover cream, Ivory Soap, tared adsorbent pads in sealed plastic bags, and antiperspirant products to be tested.

The subject will be requested to maintain normal bathing habits throughout the test period with the exception of the axillary hygiene regimen. The axillary hygiene regimen consists of washing the axillary region with Ivory Soap and water only, patting the area dry, and removing axillary hair at designated intervals during the test period. Only products supplied by the investigators may be used under the axillary region.

Sweat will be collected on tared absorbent pads taped snugly to the axillae with hypoallergenic tape. A treated and control axilla (e.g., right axilla treated with left axilla as control) will be assigned to each subject and the treated and control axillae will remain the same throughout the test period. At no time should any antiperspirant be applied to the control axilla during the test period.

Experimental Prodedure Calendar: The calendar is divided into weekly segments. Day 1 of each week is Sunday, day 2 is Monday ... day 7 is Saturday.

Week 1: Day 4 (Wednesday) begin axillary hygiene regimen as described above. Discontinue the use of present antiperspirant. Day 5-6-7 continue axillary hygiene regimen. 
Day 7 use Surgex on both axillae as directed.

Weok 2: Day 1 continue axillary hygiene regimen. Day 2-3 continue axillary hygiene regimen. Day 4-5-6 pretest sweat collection period begins using both axillae as controls. Tape the tared adsorbent pad snugly to a clean, dry axilla. Proceed with your normal daily work or routine. At the end of the allotted time period, remove the tape and place the tared adsorbent pad in the designated plastic bag and seal. These materials will be collected by the investigators. Day 7 continue axillary hygiene regimen, but no sweat will be collected. Use Surgex on both axillae as directed. Week 3: Day 1-2 continue axillary hygiene regimen. Apply test antiperspirant to premeasured area under clean, dry treated axilla. Control axilla should be washed with Ivory Soap and water only and patted dry. This two-day period is to accommodate the axillae to the antiperspirant. No sweat will be collected. Day 3-4-5 apply test antiperspirant to premeasured area under clean, dry treated axilla. Wait one minute for antiperspirant to dry, then tape tared adsorbent pad snugly to the axilla. Tape a tared adsorbent pad snugly to the clean, dry control axilla. Proceed with daily routine. At the end of the allotted time period, remove the tape, and store the pads in the designated plastic bags and seal. These materials will be collected by the investigators. Day 6-7 proceed as in week 3, day 1-2. 
Week 4: Day 7 remove axillary hair with Surgex as directed on package insert. Continue axillary hrgiene regimen. Day 1-7 is a recovery period. Continue with axillary hygiene regimen. No sweat will be collected and no test or non-test antiperspirants will be used. Week 5: Testing of a second antiperspirant begins. Proceed as in week 3.

Week 6: Recovery period. Proceed as in week 4. Apply Surgex on day 7.

Week 7: Testing of a third antiperspirant begins. Proceed as in week 3.

Week 8: Recovery period Proceed as in week 4. Apply Surgex on day 7.

Week 9: Testing of a fourth antiperspirant begins. Proceed as in week 3. Day 7 is end of testing.

Note: Effective antiperspirant concentrations of Aluminum Chlorhydrate range from 20 to 40 percent in the vehicles being tested. No adverse effects have been reported at these concentrations. 


\section{Informed Consent Form}

The Effect of Vehicle on Antiperspirant Efficacy

College of Pharmacy, University of Rhode Island, 1978

Investigators:

M. H. Smith, B.S.

Graduate Student

J. M. Lausier, Ph.D.

Associate Professor, Department of Pharmacy

G. E. Osborne, Ph.D.

Professor, Department of Pharmacy

C. T. Rhodes, Ph.D.

Chairman and Professor, Department of Pharmacy

C. I. Smith, Ph.D.

Chairman and Professor, Department of Medicinal Chemistry

Aluminum Chlorhydrate is an effective antiperspirant agent used to reduce perspiration. It is supplied normally to the consumer as the active ingredient in antiperspirant roll-on lotions, creams, solid sticks, aerosols, and manual pump sprays, which are applied topically to the axillae as needed to reduce perspiration and body odor.

The objective of this research project is to formulate typical antiperspirant products in cosmetically acceptable finished forms and evaluate gravimetrically the influence of the vehicles on antiperspirant efficiency.

Should you volunteer to participate in the project, you will be required to abstain from non-test antiperspirant/ deodorant use during the test period, remove axillary hair 
at designated intervals during the test period, and wash the axillary area with Irory Soap and water only.

You must have no broken axillary skin or sensitivities to Aluminum Chlorhydrate, Aluminum Chlorhydroxy Allantoinate, or thioglycollates. All necessary test materials will be prepared and supplied by the investigators. The antiperspirant products will contain effective levels of Aluminum Chlorhydrate in a roll-on lotion, a cream base, a solid stick, and an alcohol base (such as one used in the manual pump spray). The safety and efficacy of Aluminum Chlorhydrate as an antiperspirant are well established; it causes no damage to fabric. To minimize or eliminate sensitivity reactions and irritation to the axillary region, concentrations of $0.25 \%$ Aluminum Chlorhydroxy Allantoinate will be incorporated into the antiperspirant products. Aluminum Chlorhydroxy Allantoinate combines the astringent bacteriostatic properties of Aluminum Chlorhydrate and the sustained healing activity of allantoins. It has proven to be non-toxic, non-irritating, and even healing to irritated axillae.

To eliminate the irritation and broken skin associated with shaving of axillary hair, a safe and effective surgical depilatory, Surgex, will be used to remove axillary hair. It should not be applied to the axillae within 48 hours of shaving.

Local skin irritation or sensitization at the site of 
80

application is one possible effect of the depilatory and/or antiperspirant products. As a volunteer for this project, you may withdraw from it at any time during the investigation. You will not be identified in any publication resulting from this work.

I, - after reading and understanding the above and having the opportunity to ask questions regarding the above project now give my informed consent for participation in the antiperspirant vehicle

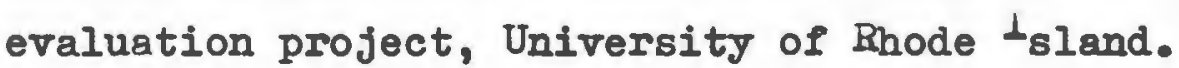

Date Signed 


\begin{abstract}
APPENDIX C
This appendix contains a sample nine-week experimental protocol calendar and weekly reminders distributed to the volunteers during this study. All the volunteers followed the test guidelines at their own homes and jobs after receiving instructions from the investigator. Distribution of these materials was well-accepted by the subjects as an aid in complying with the experimental protocol.
\end{abstract}


ANTIPERSPIRANT EXXERIMENTAL PROTOCOL

CALEMNDAR

\begin{tabular}{|c|c|c|c|c|c|c|c|}
\hline Week Day & $\begin{array}{c}1 \\
\text { SUNDAY }\end{array}$ & $\stackrel{2}{2}$ MONDAY & $\stackrel{3}{3}$ TUESDAY & $\begin{array}{c}4 \\
\text { WEDNESDAY }\end{array}$ & $\begin{array}{c}5 \\
\text { THUURSDAY }\end{array}$ & $\begin{array}{c}6 \\
\text { FRIDAY }\end{array}$ & $\begin{array}{l}7 \\
\text { SATURDAY }\end{array}$ \\
\hline 1 & & & & $\begin{array}{l}\text { BEGIN } \\
\text { March } 29\end{array}$ & March 30 & March 31 & $\begin{array}{l}\text { SURGEX } \\
\text { April } 1\end{array}$ \\
\hline$\stackrel{2}{2}$ PRETEST & April 2 & April 3 & $\begin{array}{r}\text { Swea } \\
\text { April } 4 \\
\end{array}$ & $\begin{array}{l}\text { Collecti } \\
\text { April } 5\end{array}$ & $\begin{array}{l}\text { on Pads } \\
\text { April } 6 \\
\end{array}$ & April 7 & $\begin{array}{l}\text { SURGEX } \\
\text { April } 8\end{array}$ \\
\hline AP $\stackrel{3}{T} \# 1$ & $\begin{array}{l}\text { AP T \#1 } \\
\text { April } 9\end{array}$ & $\begin{array}{l}\text { AP T \#1 } \\
\text { April } 10\end{array}$ & $\begin{array}{l}\text { Swea } \\
\mathrm{T} / \mathrm{C} \\
\mathrm{AP} \mathrm{T} \text { \#1 } \\
\text { April } 11\end{array}$ & $\begin{array}{l}\text { Collecti } \\
\text { T/C } \\
\text { AP T \#1 } \\
\text { April } 12\end{array}$ & $\begin{array}{l}\text { on Pads } \\
\text { T/C } \\
\text { AP T \#1 } \\
\text { April } 13\end{array}$ & April 14 & April 15 \\
\hline
\end{tabular}


CALENDAR--continued

\begin{tabular}{|c|c|c|c|c|c|c|c|}
\hline Week Day & $\begin{array}{c}1 \\
\text { SUNDAY }\end{array}$ & $\stackrel{2}{2}$ & $3_{\text {TUESDAY }}^{3}$ & $\begin{array}{c}4 \\
\text { WEDNESDAY }\end{array}$ & $\begin{array}{c}5 \\
\text { THURSDAY }\end{array}$ & $\stackrel{6}{\text { FRIDAY }}$ & $\stackrel{?}{\text { SATURDAY }}$ \\
\hline $\begin{array}{c}4 \\
\text { Recovery }\end{array}$ & April 16 & April 17 & April 18 & April 19 & April 20 & April 21 & $\begin{array}{l}\text { SURGEX } \\
\text { April } 22\end{array}$ \\
\hline AP $\stackrel{5}{T} \# 2$ & $\begin{array}{l}\text { AP T \#2 } \\
\text { April } 23\end{array}$ & $\begin{array}{l}\text { AP T \#2 } \\
\text { April } 24\end{array}$ & $\begin{array}{l}\text { T/C Swea } \\
\text { AP T \#2 } \\
\text { April } 25\end{array}$ & $\begin{array}{l}\text { Collecti } \\
\mathrm{T} / \mathrm{C} \\
\mathbb{A P} \text { T \#2 } \\
\text { April } 26\end{array}$ & $\begin{array}{l}\text { on Pads } \\
\text { T/C } \\
\text { AP T \#2 } \\
\text { April 27 }\end{array}$ & April 28 & April 29 \\
\hline $\begin{array}{c}6 \\
\text { Recovery }\end{array}$ & April 30 & May 1 & May 2 & May 3 & May 4 & May 5 & $\begin{array}{l}\text { SURGEX } \\
\text { May } 6\end{array}$ \\
\hline
\end{tabular}




\section{CALENDAR-continued}

\begin{tabular}{|c|c|c|c|c|c|c|c|}
\hline Week & $\stackrel{1}{1}$ & $\stackrel{2}{\text { MONDAY }}$ & $\stackrel{3}{\text { TUESDAY }}$ & $\frac{4}{\text { WEDNESDAY }}$ & $\stackrel{5}{\text { THURSDAY }}$ & $\stackrel{6}{\text { FRIDAY }}$ & SATURDAY \\
\hline AP $\stackrel{7}{T} \# 3$ & $\begin{array}{l}\text { AP T \#3 } \\
\text { May ? }\end{array}$ & $\begin{array}{l}\text { AP T \#3 } \\
\text { May } 8\end{array}$ & $\begin{array}{l}\text { Swe } \\
\text { AP T \#3 } \\
\text { May } 9\end{array}$ & $\begin{array}{l}t \text { Collecti } \\
\text { T/C } \\
\text { AP T \#3 } \\
\text { May } 10\end{array}$ & $\begin{array}{l}\text { on Pads } \\
\text { T/C } \\
\text { AP T \#3 } \\
\text { May } 11\end{array}$ & May 12 & May 13 \\
\hline $\begin{array}{c}8 \\
\text { Recovery }\end{array}$ & May 14 & May 15 & May 16 & May 17 & May 18 & May 19 & $\begin{array}{l}\text { SURGEX } \\
\text { May } 20\end{array}$ \\
\hline AP $\stackrel{9}{T} \# 4$ & $\begin{array}{l}\text { AP T } \\
\text { May } 21\end{array}$ & $\begin{array}{l}\text { AP T \#4 } \\
\text { May } 22\end{array}$ & $\begin{array}{l}\text { Swe } \\
\text { APC } \\
\text { AP } \not 4 \\
\text { May } 23\end{array}$ & $\begin{array}{l}t \text { Collecti } \\
\text { T/C } \\
\text { AP T \#4 } \\
\text { May } 24\end{array}$ & $\begin{array}{l}\text { D Pads } \\
T / C \\
\text { AP T } \not 4 \\
\text { May } 25\end{array}$ & $\begin{array}{r}\text { THE } \\
\text { May } 26\end{array}$ & $\begin{array}{l}\text { END } \\
\text { May } 27\end{array}$ \\
\hline
\end{tabular}

IMPORTANT: Continue axillary hygiene regimen with Ivory Soap throughout the test period. Apply collection pads to a clean, dry axilla.

AP T \#, antiperspirant treatment number

$\mathrm{T} / \mathrm{C}$, apply antiperspirant treatment to TREATED AXILIA, apply pads to both axillae 
Reminder Antiperspirant Volunteers

Week 2

On Saturday, April 1, 1978, use Surgex under both axillae.

On Sunday, April 2, 1978, and Monday, April 3, 1978, continue with Irory soap regimen.

On Tuesdey, April 4, 1978, collect sweat with pad provided for. 10 hours. Be sure to apply the pad marked Right Axilla to the RIGHT underarm area and the pad marked Left Axilla to the LEFT underarm area. Dermicel Cloth hypoallergenic tape is provided. Place the soft cotton side of the pad against the skin. Place the tape to the plastic covered side. Tape pad suugly to appropriate axilla. At the end of the 10-hour period, place the pad under the RIGHT axilla in the bag marked Right Axilla. Be sure to squeeze all the air out of the bag before sealing. Seal the bag securely. Do the same with the Left Axilla pad. Bring the 2 marked bags in the following morning.

On Wednesday, April 5, 1978, collect sweat for 10 hours with pads provided. Apply pads as indicated in Tuesday's procedure.

On Thursday, April 6, 1978, collect sweat for 10 hours. Apply pads as indicated in Tuesday's procedure. On Friday, April 7, 1978, continue Irory Soap regimen. 
86

On Saturday, April 8, 1978, use Surgex under both axillae.

NOTE: The Irory Soap regimen should be continued throughout the test period. 
TAME WEEK \# 3 AP TRT \# 1

Your TREATED side is the axilla. The test CREAM antiperspirant is to be applied to this axilla ONLY. Your CONTROI side is the axilla. No antiperspirant should be applied to this axilla. REMINDER: CONTINUE WASHING BOTH AXILIAE WITH IVORY SOAP AND WATER ONLY FOR THE DURATION OF THE EXPERIMENT. Application of the test CREAM antiperspirant (ap).

Note the area outlined by axillary hair under your TREATED axilla. Make a rectangle of this area. This is the area to which the ap will be applied. Apply the ap provided for the assigned day to the clean, dry TREATED axilla ONLY. The cream ap should be rubbed on the axilla with the glassine wrap. Try to use the entire sample. Allow to dry about 1 minute. Return the glassine wrap with any unused cream ap in the jar to the investigator the following morning.

The CONTROL axilla should be clean and dry. NO antiperspirant is to be applied to this axilla. SUNDAY, April 9. Apply the test CREAM ap as directed to the treated axilla only. No antiperspirant will be applied to the control axilla. The test ap may be worn for the entire day. No sweat collection pads will be worn today. MONDAY, April 10. Proceed as on SUNDAY. TUESDAY, April 11. Apply the test CREAM ap as directed to the treated axilla only. Let dry about 1 minute. Snugly 


\section{8}

tape the sweat collection pads to the designated axilla. Wear the pads for 10 hours. At the end of the 10-hour collection period, return the pads to the appropriate Ziploc bag. SEAL WELL. Return the pads and bags to the investigator the following day. WEDNESDAY, April 12. Proceed as on TUESDAY. (Sweat collection day)

THURSDAY, April 13. Proceed as on TUESDAY. (Sweat collection day)

FRIDAY, April 14. Recovery period begins. (No sweat collected)

SATURDAY, April 15. Proceed as on FRIDAY. (No antiperspirant applied and no sweat collection) 
89

WEBK \# 4

SUNDAY, April 16, to FRIDAY, April 21, is a recovery period. Continue washing axillae with Ivory Soap and water only. NO sweat will be collected. NO antiperspirant will be used.

SATURDAY, April 22. Continue above procedure. Remove axillary hair with Surgex as directed on package insert. 
TAMIS WEEK \# AP TRT \# 2

Your TREATED side is the axilla. The test IOTION antiperspirant is to be applied to this axilla only. Your CONTROI side is the axilla. NO antiperspirant should be applied to this axilla. REMINDER: CONTINUE WASHING BOTH AXILIAE WITH IVORY SOAP AND WATER ONLY FOR THE DURATION OF THE EXPERIMENT. Application of the test IOTION antiperspirant (ap).

Note the area outlined by axillary hair under your TREATED axilla. Make a rectangle of this area. This is the area to which the ap will be applied. Apply the ap provided for the assigned day to the clean, dry TREATED axilla ONLY. Apply the lotion ap with the attached cotton swab. Insert the swab into the lotion and apply to the TREATED axilla. Try to use the entire sample. Allow the ap to dry about 1 minute. Break the swab to fit inside the vial and seal tightly. Return the vial, containing the swab and any remaining lotion, to the investigator the following morning. The CONTROI axilla should be clean and dry. NO antiperspirant is to be applied to this axilla. SUNDAY, April 23. Apply the test IOTION ap as directed to the TREATED axilla only. No antiperspirant will be applied to the control axilla. The test ap may be worn for the entire day. No sweat will be collected today. MONDAY, April 24. Proceed as on SUNDAY. Tuesday, April 25. Apply the test LOTION ap as directed to 
the treated axilla only. Let dry about 1 minute. Snugly tape the sweat collection pads to the designated axillae. Wear the pads for 10 hours. At the end of the 10-hour collection period, return the pads to the appropriate Ziploc bag. SEAL WHU. Returm the pads in the bags to the investigator the following day. WEDNESDAY, April 26. Proceed as on TUESDAY. (Sweat collection day)

THURSDAY, April 27. Proceed as on Tuesday. (Sweat collection day)

FRIDAY, April 28. Recovery period begins. (No ap application and no sweat collection)

SATURDAY, April 29. Proceed as on FRIDAY. (No ap application and no sweat collection) 


\section{2}

WEEK \# 6

SUNDAY, April 30, to FRIDAY, Hay 5, is a recovery period. Continue washing axillae with Ivory Soap and water only. NO sweat will be collected. NO antiperspirant will be used. SATURDAY, May 6. Continue above procedure. Remove axillary hair with Surgex as directed on package insert. 
NAME WHEK \# AP TRT \# 3

Your TREATED side is the axilla. The test CLEAR antiperspirant is to be applied to this axilla only. Your CONIROL side is the axilla. № antiperspirant should be applied to this axilla. REMINDER: CONTINUE WASHING BOTH AXILLAE WITH IVORY SOAP AND WATER ONLY FOR THE DURATION OF THE EXPERIMENT. Application of the test CLEAR antiperspirant (ap). (The test CLEAR ap is an alcohol-based ap similar to the manual pump spray).

Note the area outlined by axillary hair under your TREATED axilla. Make a rectangle $4^{\prime \prime}$ by $2^{\prime \prime}$ of this area. This is the area to which the ap will be applied. Apply the ap provided for the assigned day to the clean, dry TREATED axilla only. Apply the CLEAR ap with the attached cotton swab. Insert the swab into the ap and apply to the TREATED axilla. Try to use the entire sample. Allow to dry about 1 minute. Break the swab to fit inside the vial and seal tightly. Return the vial containing the swab and any remaining ap to the investigator the following morning.

The CONTROI axilla should be clean and dry. No antiperspirant is to be applied to this axilla. SUNDAY, May 7. Apply the test CLEAR ap as directed to the treated axilla only. No antiperspirant will be applied to the control axilla. The test ap may be worn for the entire day. No sweat will be collected today. 
MONDAY, May 8. Proceed as on SUNDAY. (No sweat collection)

TUESDAY, May 9. Apply the ap as directed to the TREATED axilla only. Let dry about 1 minute. Snugly tape the sweat collection pads to the designated axillae. Wear the pads for 10 hours. At the end of the 10-hour collection period, return the pads to the appropriate Ziploc bag. SEAL WELL. Return the pads in the bag to the investigator the following day. WEDNESDAY, May 10. Proceed as on TUESDAY. (Sweat collection day) THURSDAY, May 11. Proceed as on TUESDAY. (Sweat collection day)

FRIDAY, May 12. Recovery period begins. (No sweat collection and no antiperspirant applied) SATURDAY, May 13. Proceed as on Friday. (No sweat collection and no antiperspirant applied) 
WEEKK \# 8

SUNDAY, May 14, to FRIDAY, May 19, is a recovery period. Continue washing axillae with Ivory Soap and water only. NO sweat will be collected. NO antiperspirant will be used. SATURDAY, May 20. Continue above procedure. Remove axillary hair with Surgex as directed on package insert. 
TAME WFझर \# AP TRT \# 4

Your TREATED side is the axilla. The test STICK antiperspirant is to be applied to this axilla only. Your CONTROI side is the axilla. NO antiperspirant should be applied to this axilla. REMINDER: CONTINUE WASHING BOTH AXILTAE WITH IVORY SOAP AND WATER ONLY FOR THE DURATION OF THE EXPERTMENT. Application of the test STICK antiperspirant (ap).

Note the area outlined by axillary hair under your TREATED axilla. Make a rectangle $4^{n}$ bJ $2^{\prime \prime}$ of this area. This is the area to which the ap will be applied. Apply the ap provided for the assigned day to the clean, dry TREATED axilla ONLY. The test stick ap may be rubbed in with your fingers or by using the glassine wrap. Try to use the entire sample. Allow to dry about 1 minute. Return the glassine wrap and any unused test stick ap in the jar to the investigator the following morning.

The CONTROL axilla should be clean and dry. NO antiperspirant is to be applied to this axilla. SUNDAY, May 21. Apply the test stick ap as directed to the treated axilla only. No antiperspirant will be applied to the control axilla. The test ap may be worn for the entire day. No sweat collection pads will be worn today. MONDAY, May 22. Proceed as on Sunday. TUESDAY, May 23. Apply the test STICK ap as directed to 
the TREATED axilla only. Let dry about 1 minute. Snugly tape the sweat collection pads to the designated axillao. Wear the pads for 10 hours. At the end of the 10-hour collection period, return the pads to the appropriate Ziploc bag. SEAI WELI. Return the pads and bag to the investigator the following day. WEDNESDAY, May 24. Proceed as on TUESDAY. THURSDAY, Maj 25. Proceed as on TUESDAY. This is the final day of the antiperspirant study. Thank you. 
VII. REPERENCES

(1) H. Baker, J. Soc. Cosmet. Chem., 20, 239 (1969).

(2) M. Barr, J. Pharm. Sci, 21, 395 (1962)

(3) C. W. Barrett, J. Soc. Cosmet. Chem., 20, 487 (1969).

(4) E. S. Bretschneider, A. M. Rubino, and J. J. Margres, J. Soc. Cosmet. Chem., 28, 441 (1977).

(5) B. Idson, J. Pharm. Sci., 64, 901 (1975).

(6) E. Jungermann, J. Soc. Cosmet. Chem., 25, 621, (1974).

(7) E. Jungermann and H. C. Silberman, J. Soc. Cosmet. Chem., 23, 139 (1972).

(8) A. Kligman, J. Am. Med. Assoc., 193, 800 (1965).

(9) M. W. Steed, J. Soc. Cosmet. Chem., 26, 17 (1975).

(10) J. Zahejsky and J. Robensky, J. Soc. Cosmet Chem., 23. 775 (1972).

(11) T. A. Bakiewicz, J. Soc. Cosmet. Chem., 24, 245 (1973).

(12) S. M. Beekman, J. M. Halbert, and H. W. Schmank, J. Soc. Cosmet. Chem., 18, 105 (1967).

(13) G. F. Collins and J, E. Christian, J..Am. Pharm. Assoc., Sci. Ed., 47, 25 (1958).

(14) T. Govett and M. G. deNavarre, Am. Perf. Ess. Oil Rev., 49, 365 (1947).

(15) A. B. G. Iansdown, J. Soc. Cosmet. Chem., 24, 677 (1973).

(16) R. E. Iux and J. E. Christian, Am. J. Physiol, 162, 193 (1.950).

(17) W. J. O'Malley and J. E. Christian, J. Am. Pharm. Assoc., Sci. Ed.., 49, 402 (1960). 
(18) C. Ukrami and J. E. Christian, J. Am. Pharm. Assoc., Sci. Ed., 42, 179 (1953).

(19) W. M. Wooding, H. E. Jass, and I. Ugelow, J. Soc. Cosmet. Chem., 15, 579 (1964).

(20) "Alcloxa Information Sheets," Schujlkill Chemical Company, Philadelphia, Pennsylvania (n. d.).

(21) "Chlorhydrol Antiperspirants: Safety and Efficacy Review," Reheis Chemical Company, Phoenix, Arizona, 1972 , p. 1.

(22) "News Highlights," FDA Consumer, May 1978, pp. 28-29.

(23) G. W. Fredell and J. Iongfellow, J. Soc. Cosmet. Chem., 2, 108 (1958).

(24) P. A. Majors and J. E. Wild, J. Soc. Cosmet. Chem., 25, 139 (1974).

(25) N. J. Van Abee, Am. Perf. Ess. Oil Rev., 88, 501 (August 1966).

(26) W. M. Wooding and P. Finklestein, J. Soc. Cosmet. Chem., 26, 255 (1975).

(27) "Chdomydrol," Reheis Chemical Company, Chicago, Illinois, 1970, p. 19.

(28) W. Montagna and P. F. Parakkal, The Structure and Function of Skin, 3rd ed., Academic Press, New York, 1974 , p. 63.

(29) E. G. Klarmann, Am. Perf. Ess. Oil Rev., 52, 33 (1948).

(30) R. I. Gross and J. N. Venson, "The Physiology and Pharmacology of Sweating," in Cosmetics: Science and Technology, vol. 3, 2nd ed., Mo S. Balsam and E. Sagarin, ed., John Wiley and Sons, Inc., New York, 1974, pp. 229-230.

(31) W. Montagna and P. F. Parakkal, op. cit., p. 334. (monograph)

(32) Ibid.; p. 367 .

(33) R. G. Harry, ed., Harry's Cosmeticology, 6th ed., Leonard Hill Books, London, 1973, p. 252 ? 
100

(34) W. B. Shelley, J. Soc. Cosmet. Chem., 2, 171 (1956).

(35) W. Montagna and P. F. Parakkal, op. cit., p. 338-339.

(36) W. B. Shelley, J. J. Hurley, Jr., and A. C. Nichols, Arch. Dermatol., 68, 430 (1953).

(37) R. I. Gross and J. N. Venson, op. cit, p. 269.

(38) M. I. Barr, The Nucleus, 54, 5 (June 1976).

(39) A. Dravnieks, J. Soc., Cosmet. Chem., 26, 551 (1975).

(40) C. Sagan, The Dragons of Eden: Speculations on the Evolution of Human Intelligence, Ballantine Books, New York, 1977, p. 72.

(41) W. C. Randal and K. K. Kimara, Pharmacological Rev., 2. 365 (1955).

(42) I. S. Goodman and A. Gilman, The Pharmacological Basis of Therapeutics, 4th ed. The Maclillan Company, New York, 1970, Pp. 524-548.

(43) R. I. Gross and J. N. Venson, op. cit., pp. 257-258.

(44) R. G. Harry, op. cit., p. 256.

(45) F. S. K. MacMillan, H. H. Reller, and F. H. Snyder, J. Invest. Dermatole, 43, 363 (1964).

(46) R. B. Stoughton, F. Chiu, W. Fritsch, and D. Nurse, J. Invest. Dermatol., 42, 151 (1954).

(47) R. I. Gross and J. N. Venson, op. cit., p. 253.

(48) R. I. Gross and J. N. Venson, op. cit., p. 231.

(49) R. G. Harry, op. cit., p. 254.

(50) Ibid., p. 253.

(51) V. Drizek and D. K. Kuzel, J. Soc. Cosmet. Chem., 22, 809 (1971).

(52) R. I. Gross and J. N. Venson, op. cit., p. 254.

(53) Handbook of Nonprescription Drugs, 5th ed., American Pharmaceutical Association, Washington, D. C., 1977, pp. 297-299. 
(54) R. G. Harry, op. cit., p. 257.

(55) N. H. Sheehadeh and A. M. Kligman, J. Invest. Dermatole, 40, 61 (1963).

(56) I. G. Berglund and R. R. Gonzalez, J. Appl. Physiol, 42, 767 (1977).

(57) R. P. Quatrale, K. I. Stoner, and C. B. Pelger, J. Soc. Cosmet. Chem., 28, 91 (1977).

(58) H. H. Reller, J. Soc. Cosmet. Chem, 15, 99 (1964).

(59) C. F. Iist and M. M. Peet, Arch. Neurol, and Physchiatry, 39, 1228 (1938).

(60) R. I. Gross and J. N. Venson, op. cit., p. 247.

(61) W. Montagna and P. F. Parakkal, op. cit., p. 406.

(62) R. I. Gross and J. N. Venson, op. cit., p. 267.

(63) W. Montagna and P. F. Parakkal, op. cit., p. 399.

(64) "Chlorhydrol," loc. cit., p. 5.

(65) "DCI Survey," Drug and Cosmet. Ind., 121, 28 (October 1977).

(66) D. P. Anonis, Drug and Cosmet. Ind., 118, 48 (February 1976).

(67) F. E. Wall, "Historical Development of Cosmetics Industry," in esmetics: Science and Technelegy, vol. 3, 2nd ed., M. So Balsam and E. Sagarin, ed., John Wiley and Sons, Inc., New York, 1974, pp. 105, 121.

(68) J.A. Cella, Am. Perf. and Cosmet., 81, 84 (October 1971).

(69) J. J. Martin, Jr., Am. Perf. and Cosmet., 84, 101 (October 1969).

(70) A. M. Rubino, Drug and Cosmet. Ind., 86, 51 (October 1971).

(71) U. S., Federal Food, Drug, and Cosmetic Act, as amended January 1975, Chapter 2, Section 201. 
(72) R. G. Harry, op. cit., p. 260.

(73) J. C. Winters, J. Soc. Cosmet. Whem,, 2, 256 (1956).

(74) S. Plechner, "Antiperspirants and Deodorants," in Cosmetics: Science and Technology, rol. 2, 2nd ed., M. S. Balsam and E. Sagarin, ed., John Wiley and Sons, Inc., New York, 1972, pp. 400-409.

(75) Ibid., p. 410:

(76) M. G. deNavarre, The Chemistry and Manufacture of Cosmetics, D. VanNostrand Company, IInc., New York, T941, p. 326.

(77) I. H. Blank and R. K. Dawes, A. M. A. Arch. Dermatol., 81,565 (1960).

(78) I. H. Blank, M. Moreland, and R. K. Dawes, Proc. Scie Sect. T. G. A., No. 27, reprint ed. (May 1957).

(79) R. G. Harry, op. cit., p. 263.

(80) C. E. Johnson and S. Shuster, J. Soc. Cosmet. Chem., 24, 15 (1973).

(81) C. M. Papa, J. Soc. Cosmet. Chem,, 17, 789 (1966).

(82) F. Hermann and M. B. Sulzberger, J. Am. Med. Assoc., 167, 1115 (June 28, 1958).

(83) E. J. Masters, N. Y. State J. Med., reprint ed. (June 15, 1960).

(84) I. Rubin, A. H. Slepyan, I. F. Wever, and I. Neuhauser, J. Am. Med. Assoc., 162, 953 (November 3, 1956).

(85) "Society Transactions," Arch. Dermatol., 100, 505 (October 1969).

(86) "Chorhydrol," 10c. cit., p. 15 (monograph).

(87) Ibid., p. 11.

(88) Ibid., p. 13.

(89) J. J. Martin, Jr., A. M. Rubino, J. I. Jones, and J. A. Lawrence, Drug and Cosmet. Ind., reprint ed. (November 1966). 
(90) "AICIOXA," Technical Data Bulletin no. 753, Schuylkill Chemical Company, Philadelphia, Pennsylvania (1975).

(91) "Chlorhydrol," loc. cit., p. 18.

(92) "Amerchol Laboratory Handbook for Cosmetics and Pharmaceuticals," Amerchol, Edison, New Jersey (1977).

(93) "Antiperspirants and Deodorants Formulary," ID-134, ICI America, Inc., Wilmington, Delaware (March 1972).

(94) "Veegum Formulary," Bulletin No. 125, R. T. Vanderbilt Company, Inc., Norwalk, Connecticut (n. d.).

(95) Interview with G. Adams, Reheis Chomical Company, Berkeley Heights, New Jersey, 15 February 1978.

(96) J. A. Lawrence, Household and Personal Products Industry, reprint ed. (September 1972).

(97) K. F. Neulinger, Cosmetics and Toiletries, 22, 65 (July 1977).

(98) "Pumpable Antiperspirants," PDD-5, ICI United States Inc., Wilmington, Delaware (May 1977).

(99) "Arlamol E," No. 102-15, ICI Americas Inc., Wilmington, Delaware (1977).

(100) J. D. Minford, J. Soc. Cosmet. Chem., 15, 311 (1964).

(101) R. I. Raymond, "Deodorants and Antiperspirants," in The Science and Technology of Aerosol Packaging, ed., I. Sciarra and L. Stoller, John Wiley and Sons, Inc., New York, 1974, pp. 347-369.

(102) W. M. Montagna and P. F. Parakkal, op. cit., p. 366.

(103) M. Uttley, J. Soc. Cosmet. Chem, 23, 23 (1972).

(104) M. Wada and T. Takagaki, Tohoku J. Exper. Med., 49, 284 (1948).

(105) C. M. Papa, Arch. Dermatol., 88, 732 (1948).

(106) C. M. Papa and A. M. Kligman, J. Invest. Dermatol., 36, 167 (1961)

(107) M. Wada, Science, 111, 376 (1950). 
(108) R. Brun, J. Soc. Cosmet. Chem,, 10, 70 (1959).

(109) R. J. James, J. Soc. Cosmet. Chem., 11, 749 (1966).

(110) W. J. O'Malley and J. E. Christian, J. Am. Pharm. Assoc.. Sci. Ed., 49, 398 (1960).

(111) "Rehydrol," Reheis Chemical Company, Phoenix, Arizona (1966).

(112) "Arlacel 165," Ho. 400, ICI Americas Inc., Wilmington, Delaware (1977).

(113) "The Croda Cosmetic and Pharmaceutical Formulary," Croda,. Inc., New York, 1976, p.9.

(114) Correspondence with R. C. Vonachen, Piber Products Division, The Kendall Company, Boston, Massachusetts, 9 March 1978.

(115) "Surgex, Hair Remover Cream," package insert, Cooper Scientific Corp., Watertown, Massachusetts (n. d.).

(116) J. I. Mrers, Fundamentals of Experimentel Design, 2nd ed., Allyn and Bacon, Inc., Boston, 1972, Chapter 10, Bection 4.

(117) W. G. Cochran and G. M. Cox, Experimental Designs, and ed., John Wiley and Sons, Inc., New Iork, 1968, p. 145.

(118) National Weather Service, State Airport, Warwick, Rhode Island (April-Mag 1978). 